\title{
Strategies for prevention of gastrointestinal cancers in developing countries: a systematic review
}

\author{
Ahmad Zia Shams ${ }^{1,2}$, \\ Ulrike Haug ${ }^{2,3}$ \\ ${ }^{1}$ Epidemiological Cancer Registry Baden- \\ Wuerttemberg, German Cancer Research \\ Centre, Heidelberg, Germany \\ ${ }^{2}$ Department of Clinical Epidemiology, \\ Leibniz Institute for Prevention Research and \\ Epidemiology, Bremen, Germany \\ ${ }^{3}$ Faculty of Human and Health Sciences, \\ University of Bremen, Bremen, Germany
}

Background Gastrointestinal cancers account for one third of total cancer incidence and mortality in developing countries. To date, there is no systematic synthesis of evidence regarding strategies to prevent gastrointestinal cancers in developing countries. We aimed to provide a systematic overview of studies evaluating strategies for prevention or early detection of the three most common gastrointestinal cancers (gastric, liver and colorectal cancer) in developing countries.

Methods We searched MEDLINE, Web of Science and WHO Global Index Medicus databases for relevant articles published until October 2016 using combinations of the search terms "gastrointestinal", "digestive system", "gastric", "liver", "colorectal", "cancer", "prevention", "early detection" and "developing country" (including names).

Results Overall, 73 articles met the inclusion criteria, providing information on short- and long-term outcomes (up to 30 years) from various intervention studies ( $45 \%$ randomized). Trials on hepatitis B vaccination consistently showed vaccine efficacy over time and indicated long-term preventive effects on liver cancer incidence that start to become measurable at the population level. Studies on anti-H. pylori treatment suggested a reduction in gastric cancer incidence reaching statistical significance after long-term follow-up, while evidence regarding a preventive effect in persons with precancerous lesions is still inconclusive. The studies regarding colorectal cancer focused on early detection, $90 \%$ of which were restricted to intermediate endpoints.

Conclusion In conclusion, there were a number of studies on gastric and liver cancer prevention in developing countries showing promising results after long-term follow-up. Important next steps include pooled meta-analyses as far as possible given the heterogeneity between studies as well as implementation research.

Cancer is a leading health burden and cause of death worldwide, with approximately 14 million new cases and 8 million deaths per year globally [1]. Despite the general understanding that cancer is primarily a problem of the (industrially) developed world, more than 60\% of cancer cases and $70 \%$ of cancer deaths were estimated to occur in developing countries in 2008 [2]. Gastrointestinal cancers (GICs) are estimated to account for one third of total cancer incidence and mortality in developing countries [1]. With almost 2 million new cases and 1.5 million deaths in 2012, gastric, liver and colorectal cancers (CRC) are currently estimated to be the three most common GICs in the less developed regions of the world, where they account for $24 \%, 23 \%$ and $22 \%$ of all GICs, respectively [1]. 
Despite extensive efforts to improve treatment of metastatic disease including the development of new drugs, the prognosis for advanced stages of gastric, liver and colorectal cancer remains poor even in developed countries, with 5-year relative survival rates (regional and distant stages combined) of 33\%, 8\% and $49 \%$ in the US in 2016, respectively [3]. These figures highlight the need for further efforts to realize the high potential of primary prevention and early detection of these GICs. This is particularly relevant for developing countries where up-to-date treatment of advanced stage cancers may additionally be limited due to infrastructure and economic constraints.

To date there has been no systematic review regarding strategies to prevent these GICs in developing countries. We therefore aimed to conduct a systematic literature search and provide an overview of studies evaluating strategies for prevention or early detection of the three most common gastrointestinal cancers (gastric, liver and colorectal cancer) in developing countries.

\section{METHODS}

\section{Search strategy}

We searched MEDLINE, Web of Science and WHO Global Index Medicus databases for articles published until October 2016. We used a comprehensive search strategy with no restriction regarding publication date, type of participants (eg, age or sex characteristics), type of interventions, study design or type of outcome measures. A detailed description of our search strategy is provided in Appendix S1 in Online supplementary document. In brief, we used both free text keywords and for the MEDLINE search also MeSH (Medical Subject Heading) terms. Regarding the latter, we used the MeSH terms gastrointestinal cancer, digestive system cancer (entailing gastric, colorectal and liver cancer as MeSH sub-categories), prevention, early detection of cancer, and developing country, as search terms.

We used the United Nations Development Programme (UNDP) country classification (for the year 2013), which utilizes Human Development Index (HDI) as basis of country groupings, for determining countries with "developing" status. The classification groups all countries in very high, high, medium and low HDI clusters. Countries with high, medium and low HDI are classified as developing countries. Consequently, the names of 140 developing countries were also used as search terms. The names of these countries are listed in Appendix S2 in Online Supplementary Document. In addition to the database searches, we employed cross-referencing to complement the study identification process. Duplicate publications were deleted. In a first step, each title and abstract was screened, to determine whether the article was potentially relevant for the review topic. In a next step, the full text of potentially relevant articles was reviewed to assess whether inclusion criteria were fulfilled. This was done independently by both authors.

\section{Inclusion and exclusion criteria}

We included studies that aimed at evaluating strategies for prevention of gastric, liver and colorectal cancer in developing countries. We only included studies on humans published in English. We focused on studies that reported disease-related outcomes such as long-term health outcomes (eg, reduction of incidence or mortality) or intermediate outcomes that are expected to be associated with long-term effects (eg, detection rates or vaccine efficacy). Accordingly, we excluded non-original articles (eg, case reports, commentaries, guidelines etc.) and studies that were restricted to health behavior.

\section{Data extraction}

All studies meeting the inclusion criteria were categorized by cancer type (gastric cancer, liver cancer, colorectal cancer). Within these categories, we ordered the studies by the type of intervention or preventive strategy. We extracted the following information in a standardized manner from all included studies: author, publication year, preventive measure including details such as the intensity and length of interventions or the number of screening rounds, country and region within the country, study design, study population (sample size, sex distribution and age), outcomes under study and results. If the same study population was examined at different time points after the intervention, we extracted the information on the outcomes under study and results for each follow-up. Both authors reviewed the articles independently and any disagreement was resolved by consensus.

We applied the Preferred Reporting Items for Systematic Reviews and Meta-Analyses (PRISMA) guidelines criteria as far as it was possible, given the heterogeneity of the studies. The PRISMA Checklist is provided in Appendix S3 in Online Supplementary Document. 


\section{RESULTS}

Overall, our initial search yielded 7315 entries. After deleting duplicates $(n=765)$ and excluding articles that were not relevant to the topic according to their title and abstract $(n=6467), 83$ articles were selected for the full text review. Of these, 55 articles were relevant. Another 18 relevant articles were identified by cross-referencing, yielding in total 73 articles (Figure 1). The underlying number of studies is lower $(n=54)$ because several articles refer to the same study but report on different follow-up periods or outcomes.

\section{Gastric cancer}

Studies on gastric cancer prevention could be classified into three main categories: supplementation with vitamins and minerals (4 randomized trials), anti-H. pylori treatment (12 randomized trials) and early detection with an occult blood bead detector, with photofluorography, with X-ray or direct gastroscopy ( 5 cross-sectional diagnostic studies, 2 case-control studies and 1 non-randomized intervention trial). Table 1 provides detailed information about these studies [4-34].

Studies on vitamin and mineral supplementation (eg, vitamin A, B vitamins, selenium etc.) considered reduction in gastric cancer incidence and mortality $[4,6,7,9,10]$ or changes regarding precancerous lesions as outcomes $[5,8,11]$. All these studies were conducted in China except one [11]. The duration of supplementations ranged between 2-6 years and follow-up periods between 5 and 26 years.

The supplementation of a combination of beta-carotene, vitamin E and selenium showed a (marginally) statistically significant reduction in gastric cancer mortality of $20 \%$ (relative risk $(R R)=0.79,95 \%$ confidence interval (CI) 0.64-0.99) [4]. Other studies, partly conducted in high-risk subjects did not show statistically significant effects [5-11].

Studies on anti-H. pylori treatment considered reduction in gastric cancer incidence and mortality $[15,17,20,21]$ or other outcomes eg, changes regarding precancerous lesions or $H$. pylori cure rate [1214,16,18,19,22-26]. Eleven studies were conducted in China [13-17,19-22,24,26] and four studies in

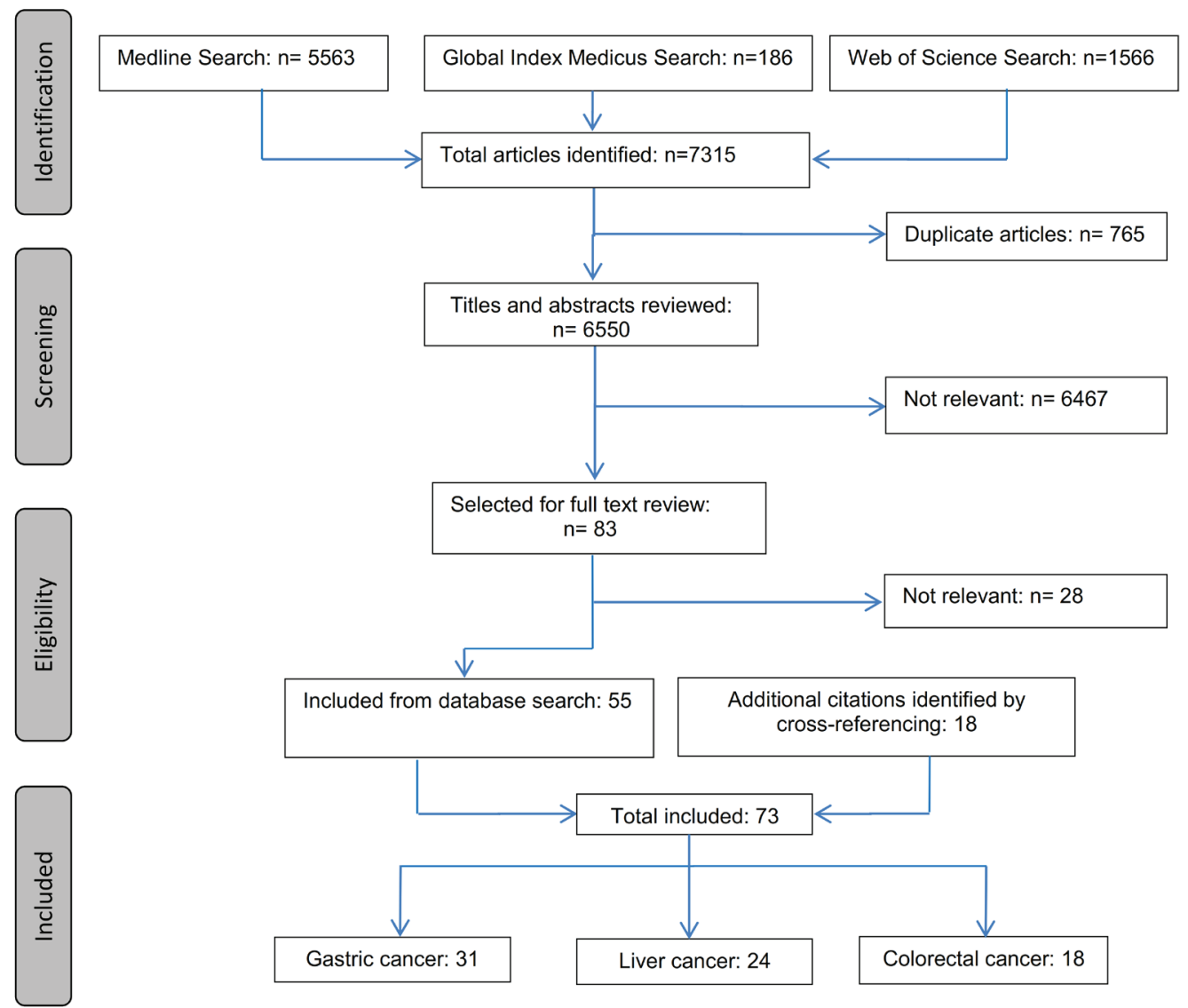

Figure 1. Flow diagram of the literature search process. 


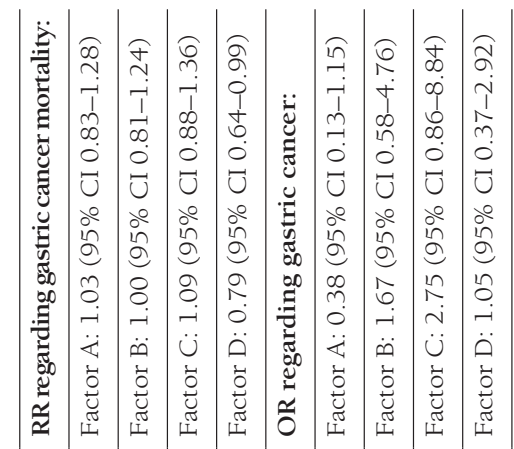

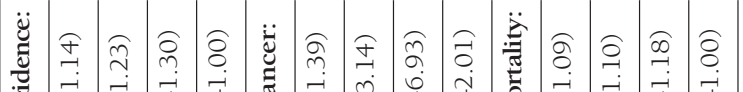

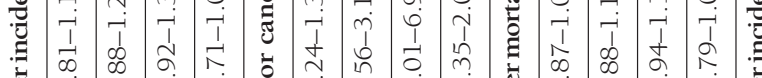

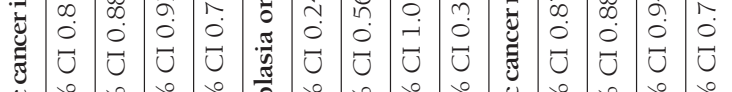

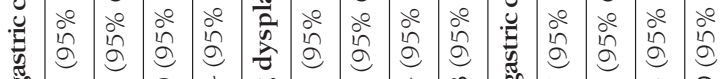

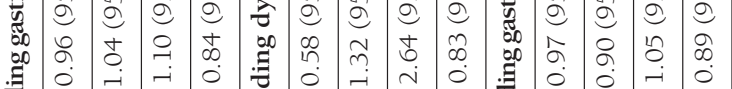

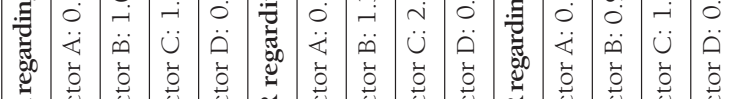

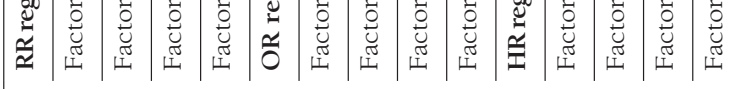

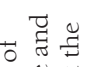

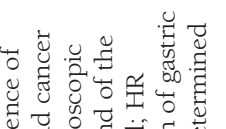

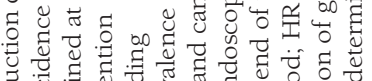

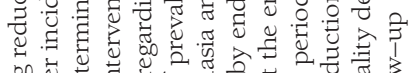

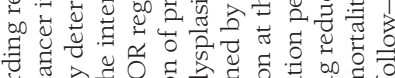

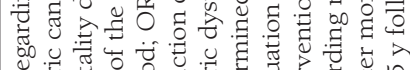

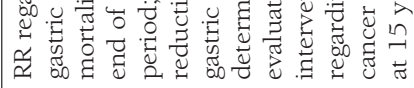
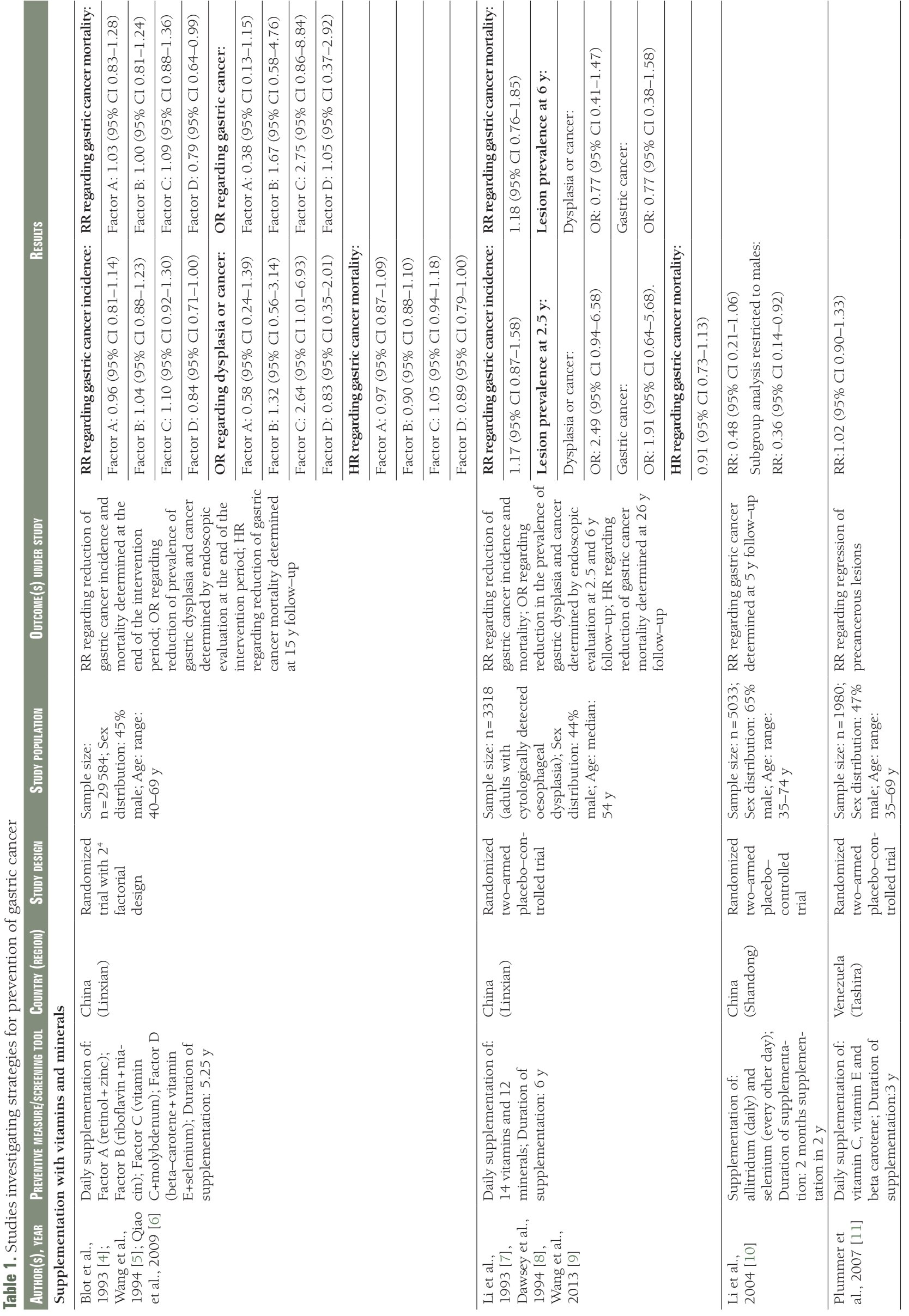

$\ddot{\hat{\imath}}$ 


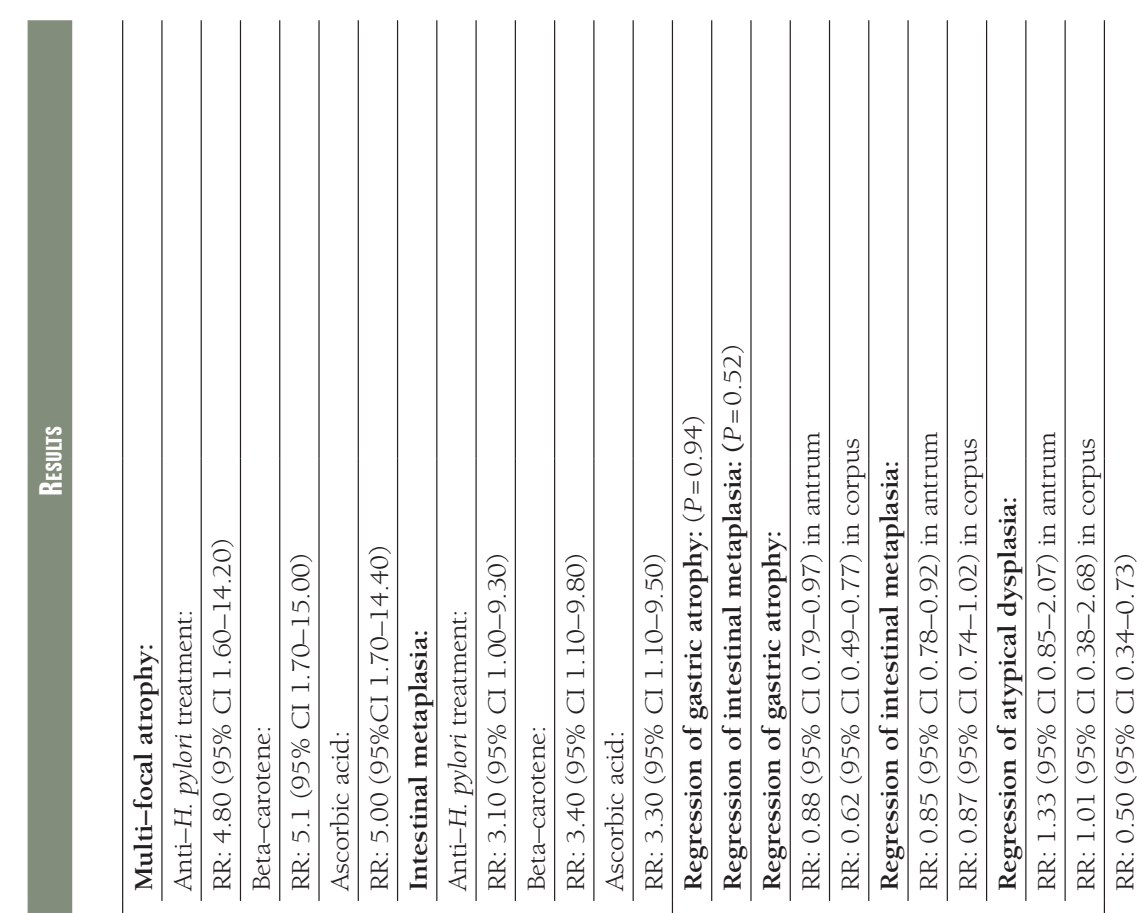

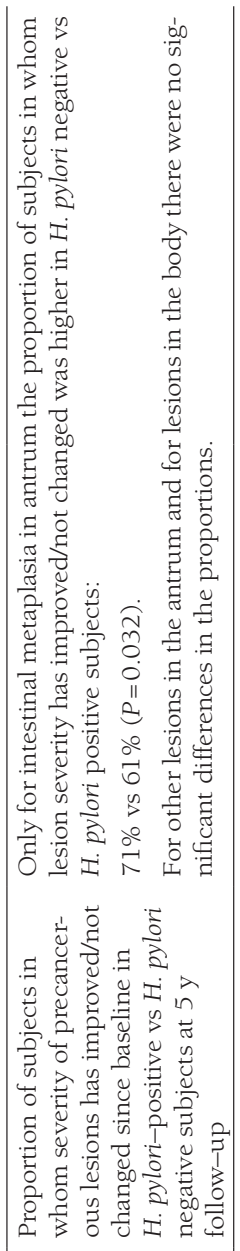

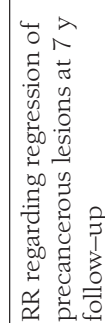

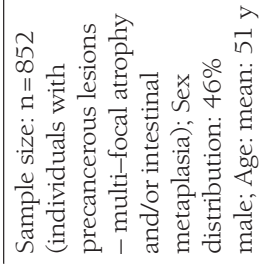

苟

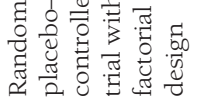

을

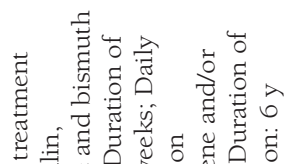

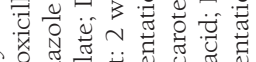

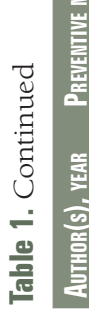

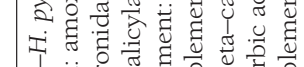

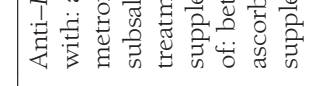

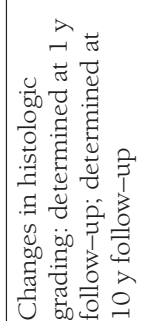

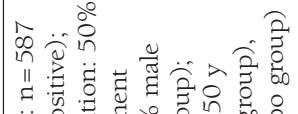

o

N.

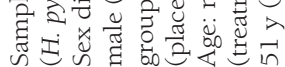

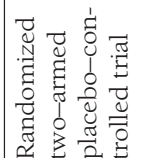

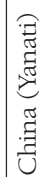

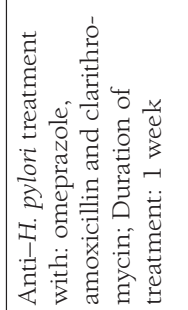

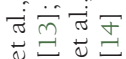

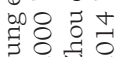

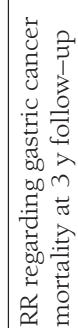

吾产

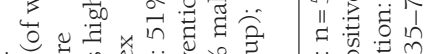

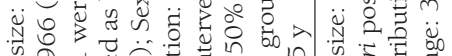
क人 을을 長 II II

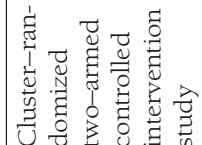

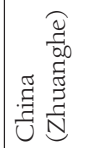

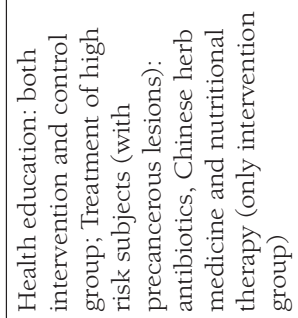

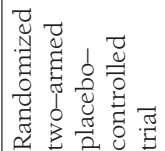

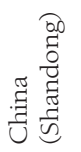

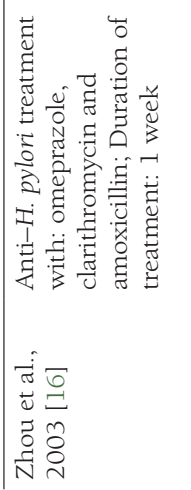



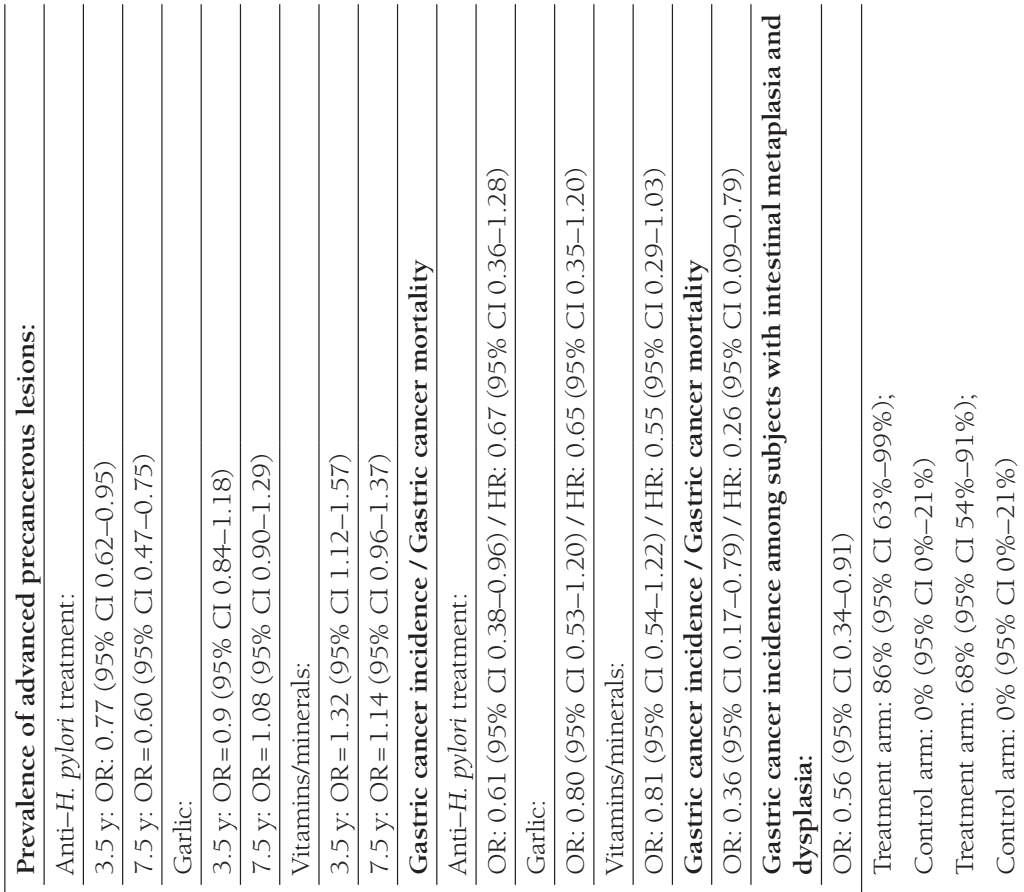

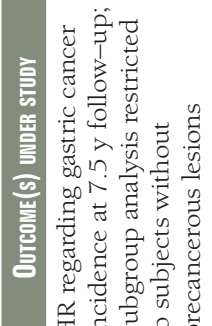

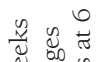

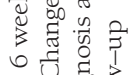

च

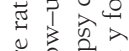

ป气 0.0

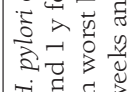

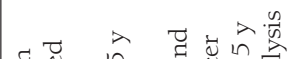

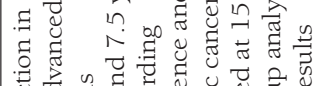

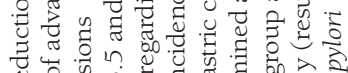

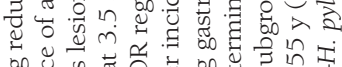

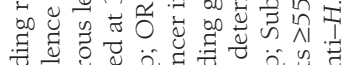

跣

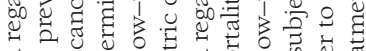

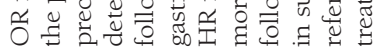

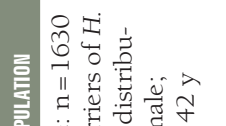

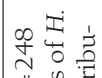

药

它成

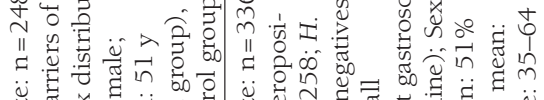

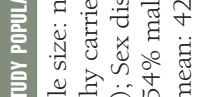

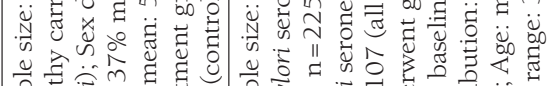

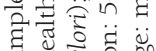

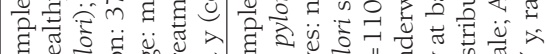

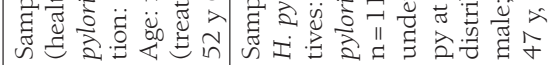

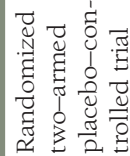

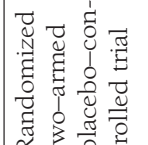

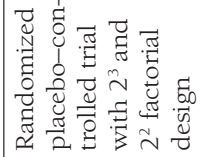

芯

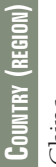

产

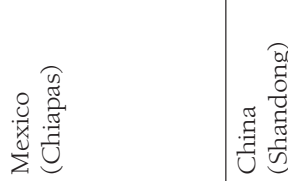

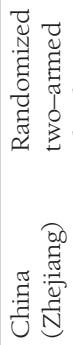

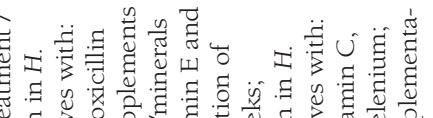

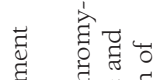

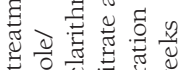

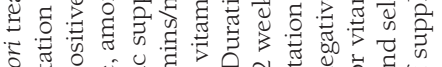

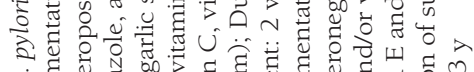

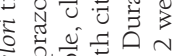

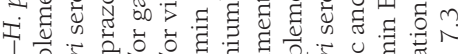

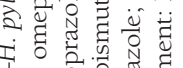

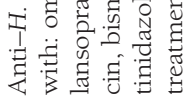

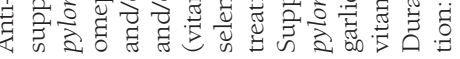

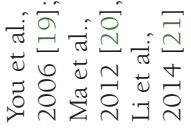

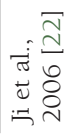




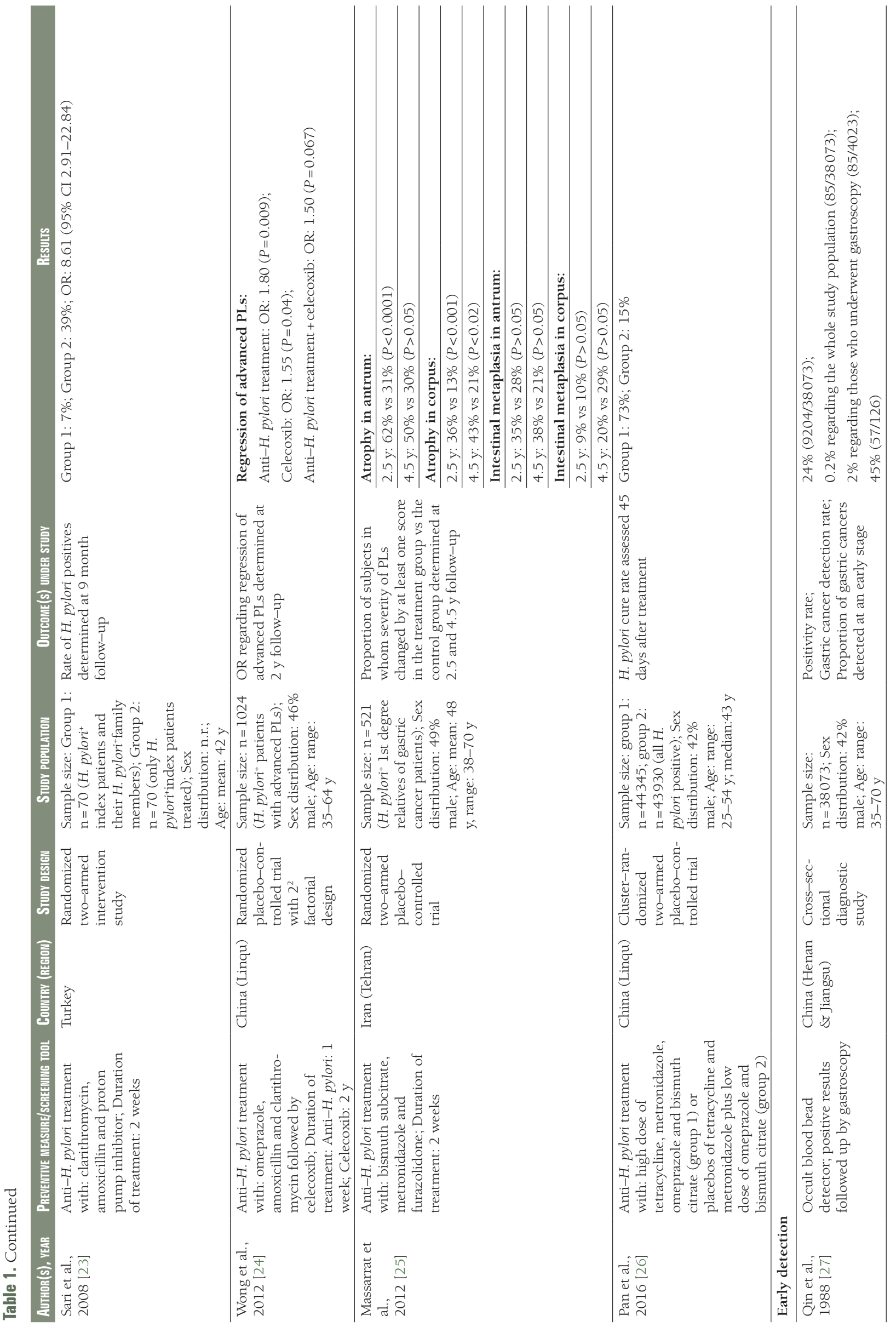




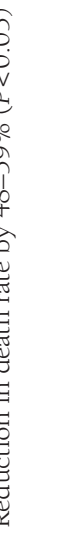

迎跤

总话全

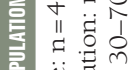

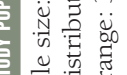

言

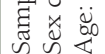

穱

岁蒙

言

过
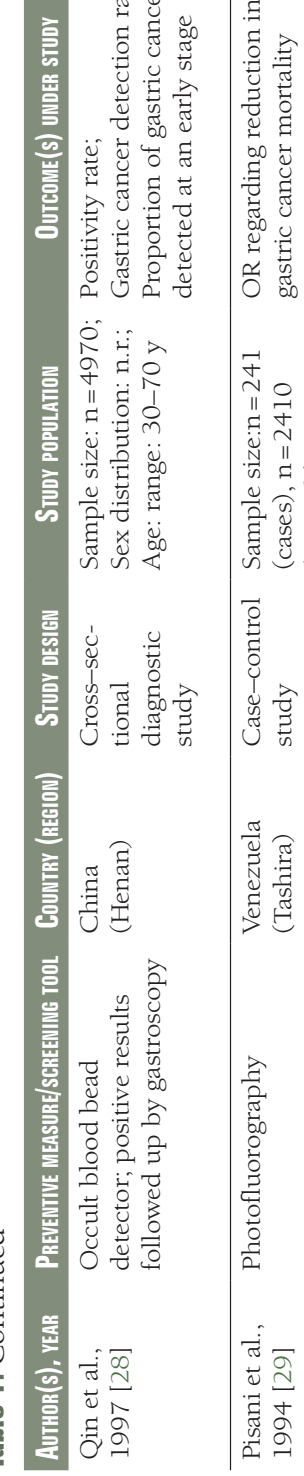

告

च.

ô.

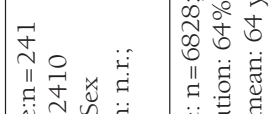

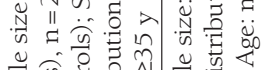

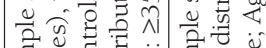

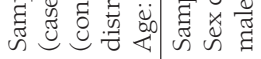

을

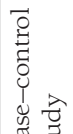

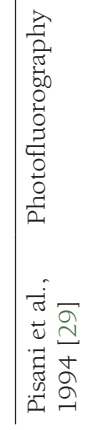

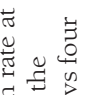

苛落

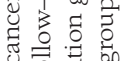

足司

品氬

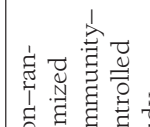

(1)

离

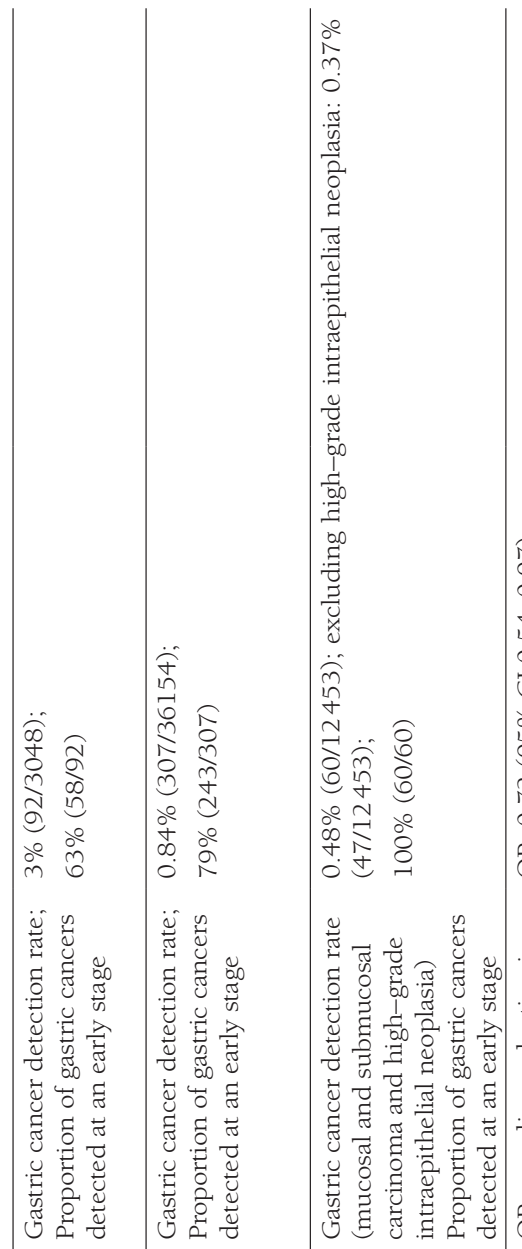

|

कि के के

O

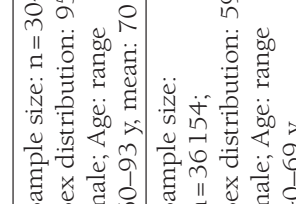

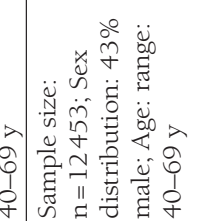

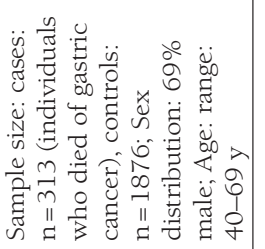

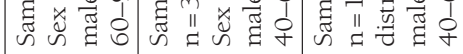

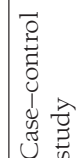

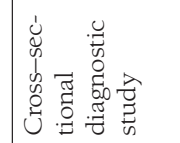

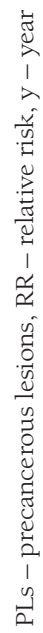
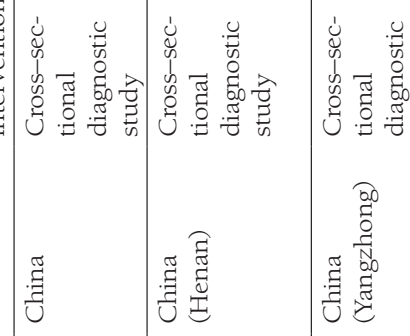

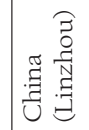
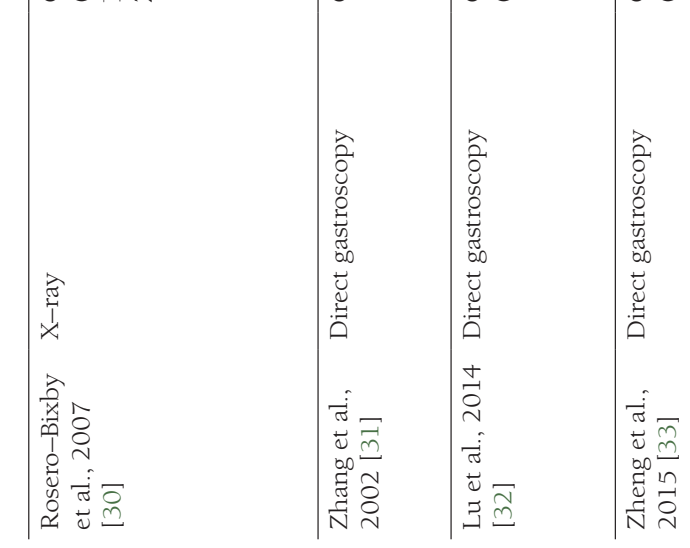

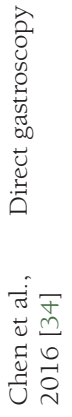

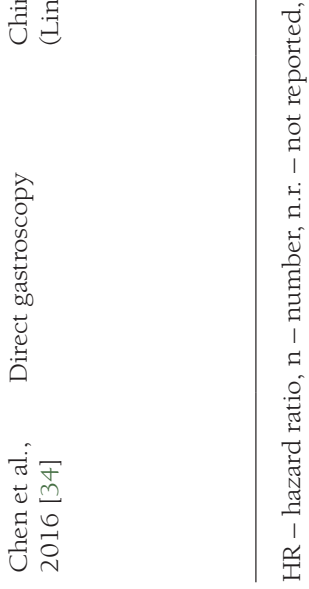


Colombia [12], Mexico [18], Turkey [23] and Iran [25]. The follow-up period ranged between 1-15 years. Nine studies used anti-H. pylori treatment $[13,14,16-18,22,25,26]$ only, and six studies also considered other substances eg, vitamins, garlic, celecoxib [12,15,19-21,24]. The antibiotics regimens used for anti-H. pylori treatment varied across studies. Gastric cancer incidence and mortality tended to be reduced by $40-50 \%[15,17,20]$. The study by Guo et al. treating high risk subjects with antibiotics and Chinese herb medicine suggested a statistically significant reduction in gastric cancer mortality $(R R=0.50$, 95\% CI 0.34-0.73) at 3 years follow-up [15]. The study by Ma et al. found a statistically significant reduction in gastric cancer incidence (odds ratio $(\mathrm{OR})=0.61,95 \%$ CI $0.38-0.96)$ but not in mortality 15 years after anti-H. pylori treatment [20]. A subgroup analysis of the same study restricted to persons 355 years or older found a statistically significant reduction in gastric cancer incidence (OR $=0.36,95 \% \mathrm{CI}$ $0.17-0.79$ ) and mortality (hazard ratio (HR) $=0.26,95 \%$ CI 0.09-0.79) [21]. This study also found a reduction in gastric cancer incidence in persons with precancerous lesions $(\mathrm{OR}=0.56,95 \% \mathrm{CI} 0.34-0.91)^{1}$, while the study by Wong et al. only found such an effect in persons without precancerous lesions $(P=0.02)$ [17]. Of the studies investigating the impact of anti-H.pylori treatment on precancerous lesions [12$14,16,25,29]$, four differentiated according to the type of lesions and found a regression mainly for atrophy while there was no or only a marginal effect regarding intestinal metaplasia $[12,14,16,25]$. Apart from anti-H. pylori treatment, one study using a factorial design suggested an effect regarding regression of precancerous lesions also for celecoxib (OR=1.50, $P=0.067)$ [24]

Studies on gastric cancer screening considered reduction in gastric cancer mortality or intermediate outcomes (eg, gastric cancer detection rate) as outcomes. Observational studies suggested a statistically significant reduction of gastric cancer mortality for direct gastroscopy (odds ratio $(\mathrm{OR})=0.72,95 \% \mathrm{CI} 0.54$ $-0.97)$ and $X-$ ray $(48-59 \%, P<0.05)[30,34]$. Screening with photofluorography was not found to reduce mortality from gastric cancer [29]. In the two studies on gastric cancer screening evaluating an occult blood bead detector (a device that is swallowed and then retrieved to detect occult blood in the stomach) the positivity rate ranged between $7-24 \%$ and the proportion of early stages of gastric cancers ranged between $45-85 \%[27,28]$. With gastroscopy, proportion of gastric cancers detected at an early stage ranged between 60-100\% [31-33].

\section{Liver cancer}

Studies on liver cancer prevention could be classified into three main categories: hepatitis B virus (HBV) immunization ( 2 randomized trials, 2 cohort studies, 1 intervention trial and 2 cross-sectional studies), liver cancer screening ( 2 randomized trials and 1 screening pilot study) and supplementation with minerals ( 1 non-randomized and 2 randomized trials). Table 2 summarizes information from these studies [35-58].

Almost all HBV immunization studies assessed the effect of $\mathrm{HBV}$ vaccine in protecting against hepatitis B chronic carriage [35-47,49,50]. Two studies evaluated reduction in incidence of liver cancer in children and young adults [38,48]. All studies used plasma-derived hepatitis B vaccines except for one study [45] that used both plasma-derived and recombinant vaccines. Vaccination regimens varied widely in terms of dosage, number of vaccinations and time intervals between vaccinations. Reported follow-up period ranged between $1-30$ years.

Reduction in the incidence of Hepatitis B surface Antigen (HBsAg) carrier state (ie, protection against chronic carriage) was consistently shown across studies, ranging between 65\%-95\% compared to nonvaccinated controls, and the effect remained stable during follow-up [35-47,49,50]. A cluster-randomized trial on HBV vaccination in newborns suggested a statistically significant reduction in liver cancer incidence in younger adults ( $\mathrm{HR}=0.16(95 \% \mathrm{CI} 0.03-0.77)$ and similarly, an incidence reduction was observed in a retrospective cohort study $(P=0.007)[38,48]$.

One study evaluated the effect of four combinations of various vitamins and minerals (eg, retinol and zinc or vitamin C and molybdenum etc.) regarding reduction of liver cancer mortality and did not show statistically significant effect [53]. Two studies conducted in China evaluated the effect of supplementation of selenium regarding liver cancer incidence in the general population and in HBsAg carriers. They suggested a reduction in age-adjusted incidence over time in the intervention group as compared to the control but it was not reported whether this was statistically significant $[51,52]$.

Two studies investigated biannual testing of serum alpha fetoprotein to screen for liver cancer in highrisk subjects [54-57]. One study reported a statistically significant reduction in liver cancer mortality by $40 \%$ after 5 years of follow-up (RR $=0.63,95 \%$ CI 0.41-0.98) [56]. The other study, however, did not 

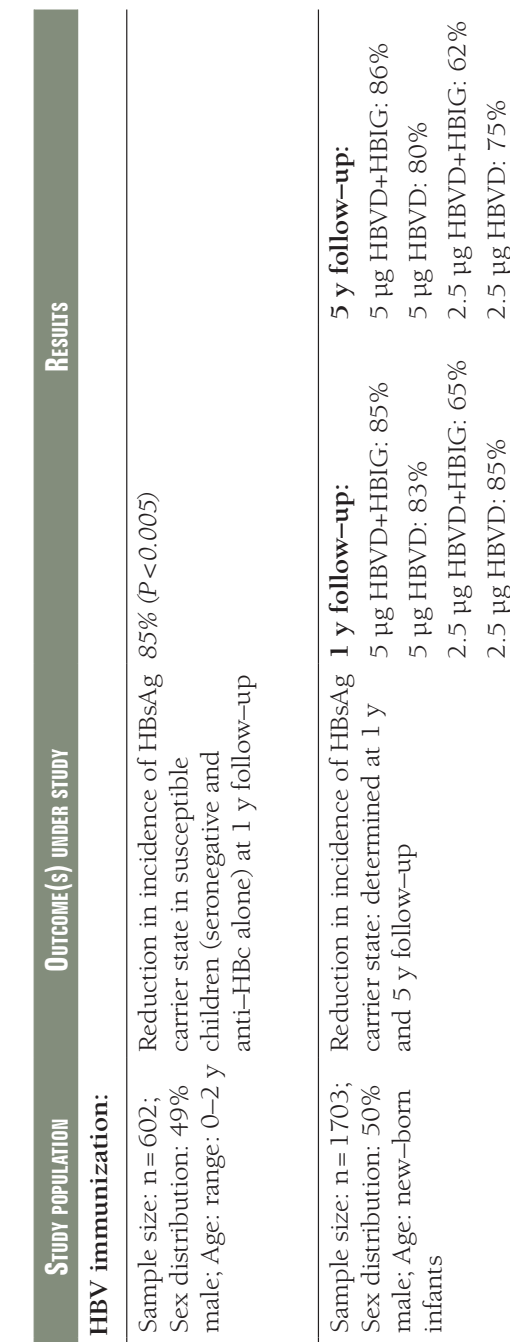

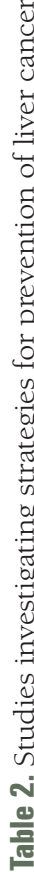

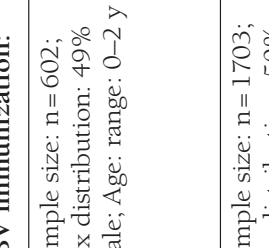
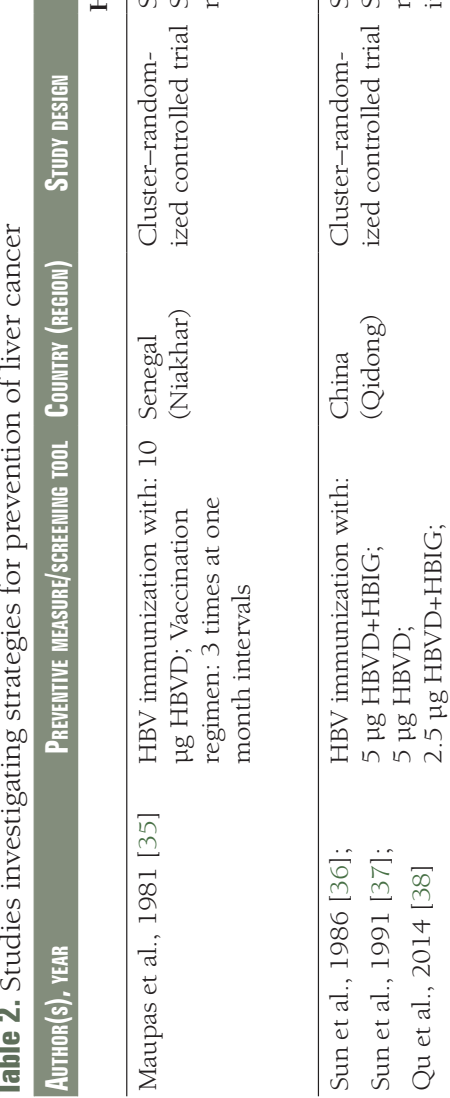

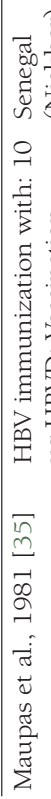

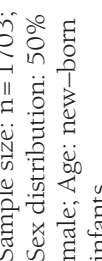

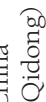

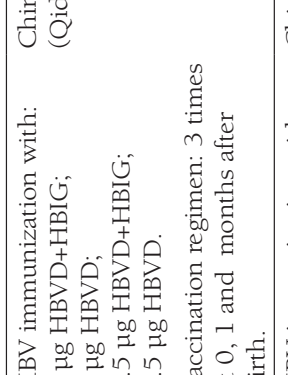

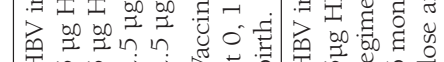

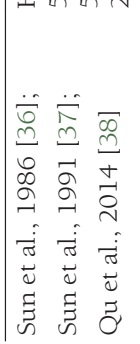

氶

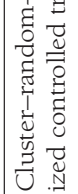

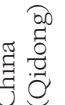

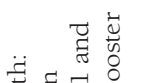

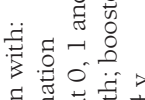

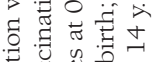

N.

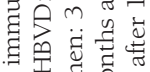

$R$
$R$
0
1
0
0
0
0
0
0
0
0
0
0
0
0
0

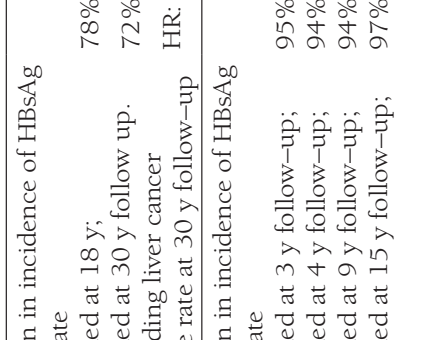

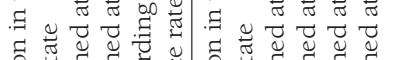

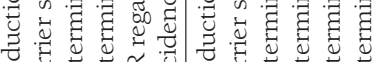

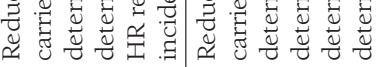
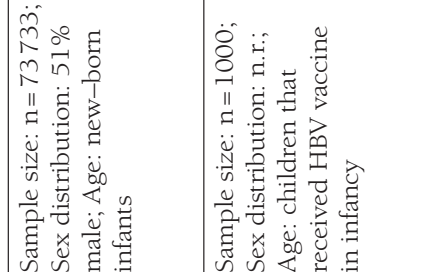

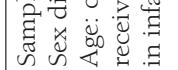
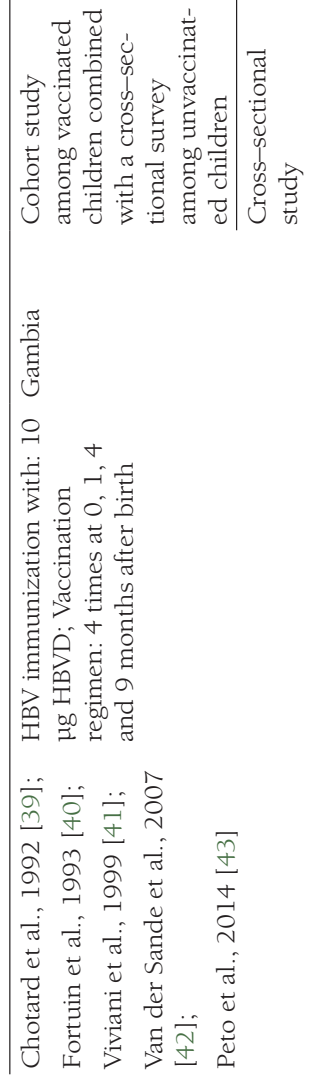

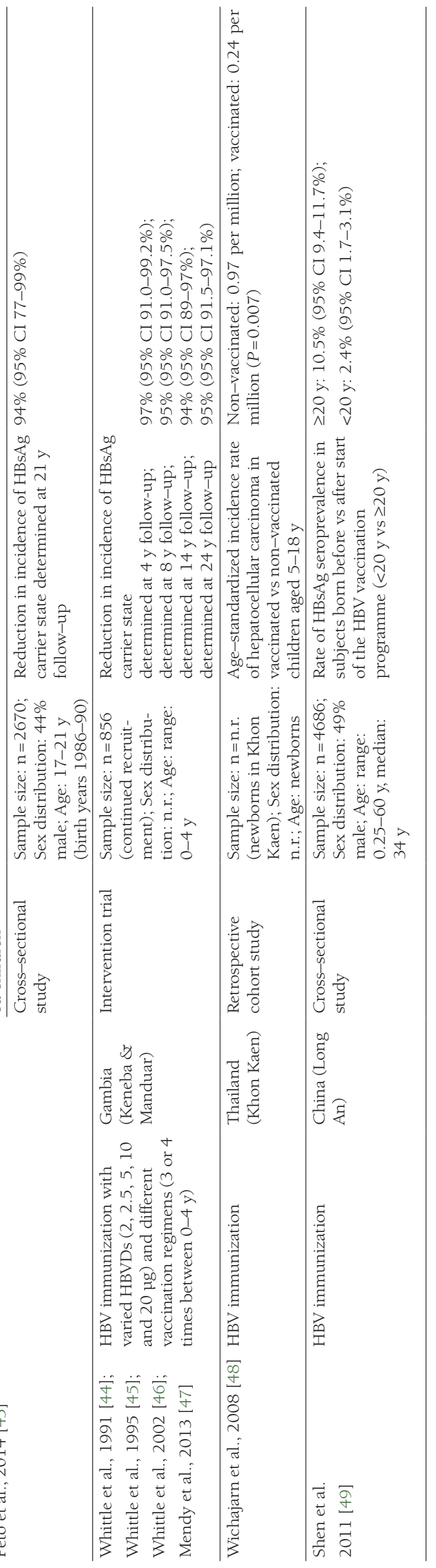




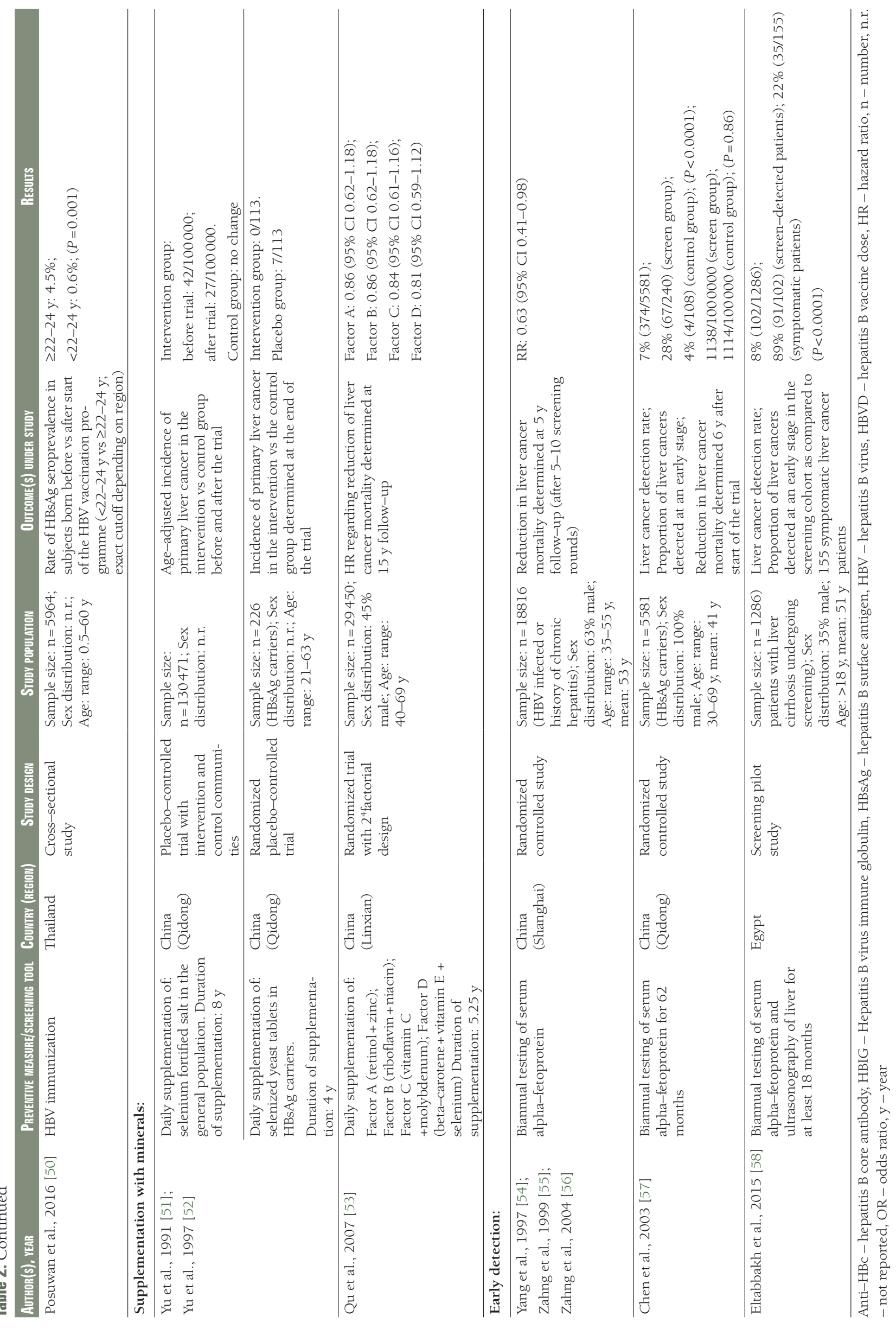


suggest a statistically significant reduction in liver cancer mortality $(P=0.86)$. One study evaluated combination of biannual testing of serum alpha fetoprotein and liver ultrasonography to screen for liver cancer and reported that the proportion of liver cancers detected at an early stage was 90\% [58].

\section{Colorectal cancer}

With respect to CRC prevention, 18 screening studies conducted mainly in average-risk subjects were identified. They investigated colonoscopy ( 6 cross-sectional diagnostic studies and 1 screening pilot study), rectoscopy ( 1 cross-sectional diagnostic study and 1 cohort study with external control group), and fecal occult blood testing ( 2 cross-sectional diagnostic studies and 7 screening pilot studies). Table 3 summarizes information about these studies [59-76].

In colonoscopy studies, CRC detection rates were between 0.5-6\% [61-67]. One study assessed proctoscopy with regular endoscopic follow-up of persons in whom precursor were removed. It suggested a reduction in rectal cancer incidence and mortality of $31 \%$ and $18 \%$ at 20 years follow-up, respectively, when compared to an external control group [60]. Three studies reported a participation rate above $40 \%$ for colonoscopy in first-degree relatives of CRC patients $[62,63,66]$.

In studies on fecal occult blood testing, CRC detection rates were directly associated with positivity rates in five of six studies [68,70-74]. The lowest CRC detection rate $(0.06 \%)$ was reported from a study on sequential fecal occult blood testing [68]. The highest positivity rates were reported from studies using fecal immunochemical testing for hemoglobin (FIT) [70-74]. The proportion of early stages among detected CRCs ranged between 47-94\% [68,70-72]. Two studies investigated the potential of risk stratification using a clinical risk score combined with FIT [75,76]. One of these studies found a five-fold higher rate of advanced neoplasia among those with both a high-risk score and a positive FIT result as compared to those with a moderate-risk score and a negative FIT result [76]. The other study, a clusterrandomized study, suggested a reduction in CRC mortality after 8 years follow-up [75]. Five studies reported participation rates for fecal occult blood testing above $60 \%[68,70,72-74]$.

\section{DISCUSSION}

Our systematic review identified a wide range of studies evaluating strategies for prevention of GICs in developing countries, including follow-up reports up to 30 years. Studies on gastric and liver cancer prevention showing promising results only after long-term follow-up illustrate the particular challenge of generating evidence in cancer prevention.

The development and evaluation of strategies for cancer prevention is a long-lasting process. The duration of this process is amongst others determined by the natural history of the disease, ie, the time that it takes until risk factors, precursor lesions or preclinical cancer stages would have impacted on the disease incidence or mortality if they had remained unchanged or untreated. If the interruption of the natural history takes place at an early phase in life, the time lag until a potential effect is measurable at the population level is further prolonged.

The studies included in our review on anti-H. pylori treatment to prevent gastric cancer can be considered as an example where the process of developing a preventive strategy takes long. With a follow-up time of 7.5 years after $H$. pylori treatment the randomized controlled trial by Wong et al. found an incidence reduction of $40 \%$ for gastric cancer but this effect did not reach statistical significance [17]. With a follow-up time of 15 years Ma et al. found a similar effect that was statistically significant. Regarding the effectiveness of anti-H. pylori treatment in persons who already have precancerous lesions the evidence is still not conclusive. Some but not all studies found a regression of precancerous lesions after $H$. pylori treatment. One study reported a preventive effect only in subgroup analysis restricted to persons without precancerous lesions [17]. A recent study by Li et al. analyzing 15-year follow-up data suggested a reduction in the incidence of gastric cancer by $40 \%$ among subjects with intestinal metaplasia and dysplasia treated against $H$. pylori at baseline [21]. As for vaccination programs, H. pylori treatment is a preventive measure that can be completed within a narrow time window and does not need to be repeated on a regular basis, which is an important aspect in view of large-scale feasibility and acceptance.

The studies included in our review on HBV vaccination published in 1981 and later can be considered as an example where the process to develop a preventive strategy that is widely accepted and applied was relatively short. Robust evidence showed that vaccine efficacy against chronic carriage of HBV was as high as $65-95 \%$ across studies and remained stable with time. Since 1992 the World Health Organization 


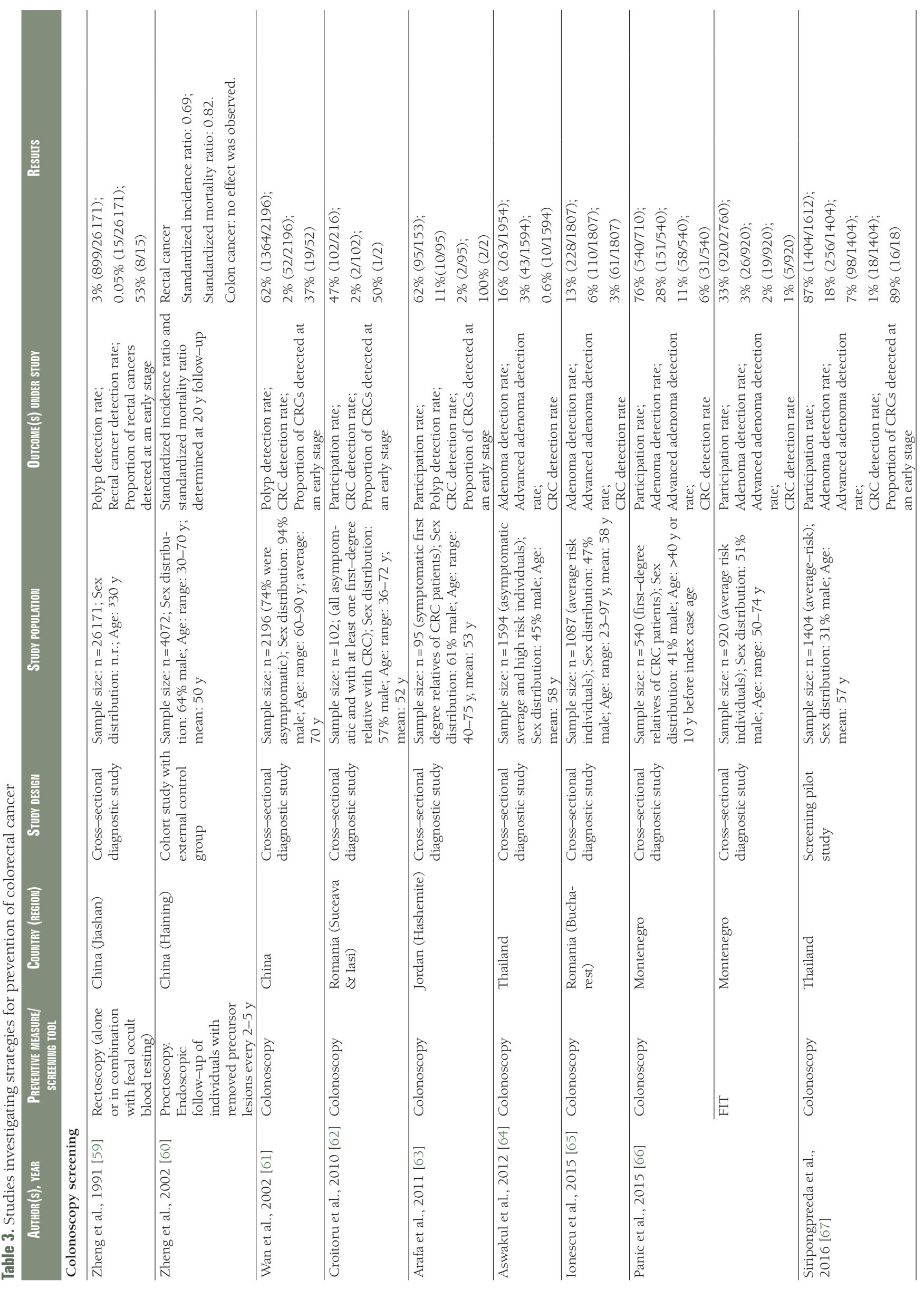




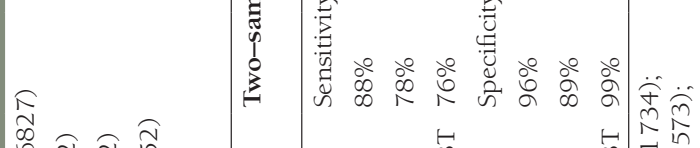

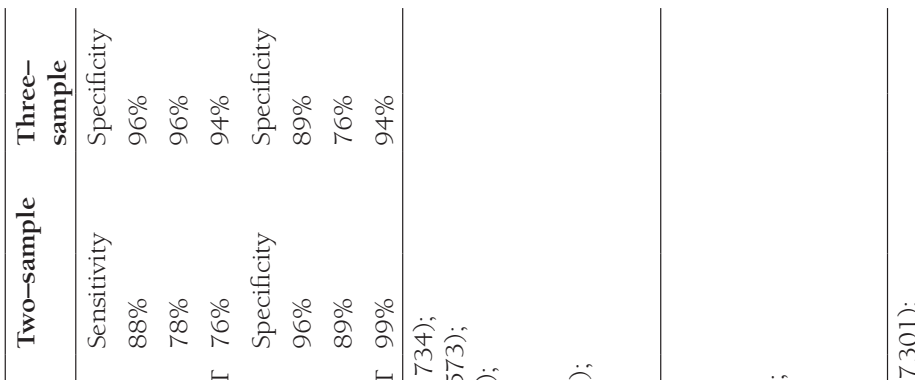

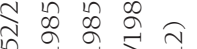

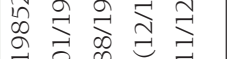

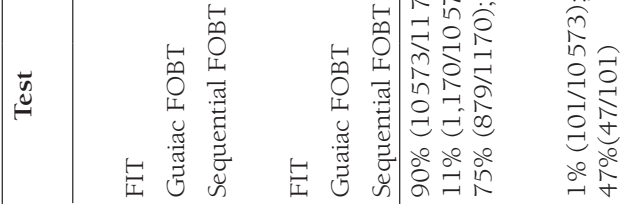

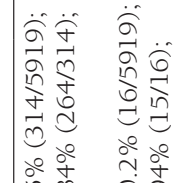

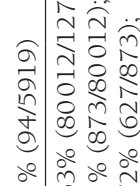

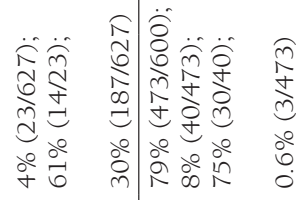

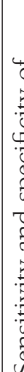

劳

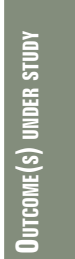

苞

品

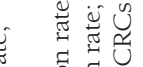

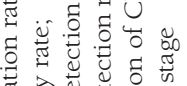

कीज

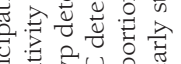

氙:

全全范

氙.

氙

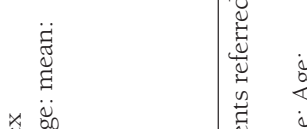

흠

诧皆

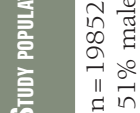

ํํํ.

至

范

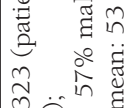

III

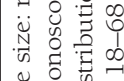

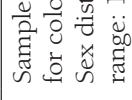

觔㣢

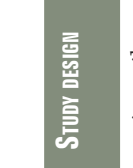

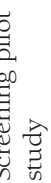

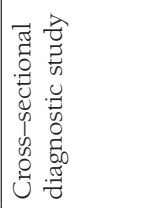

言

苞

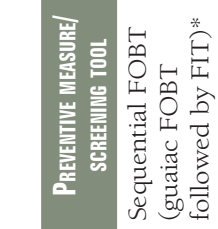

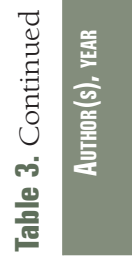

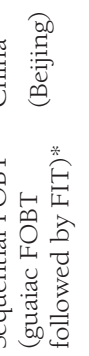

㸓氬

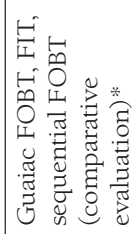
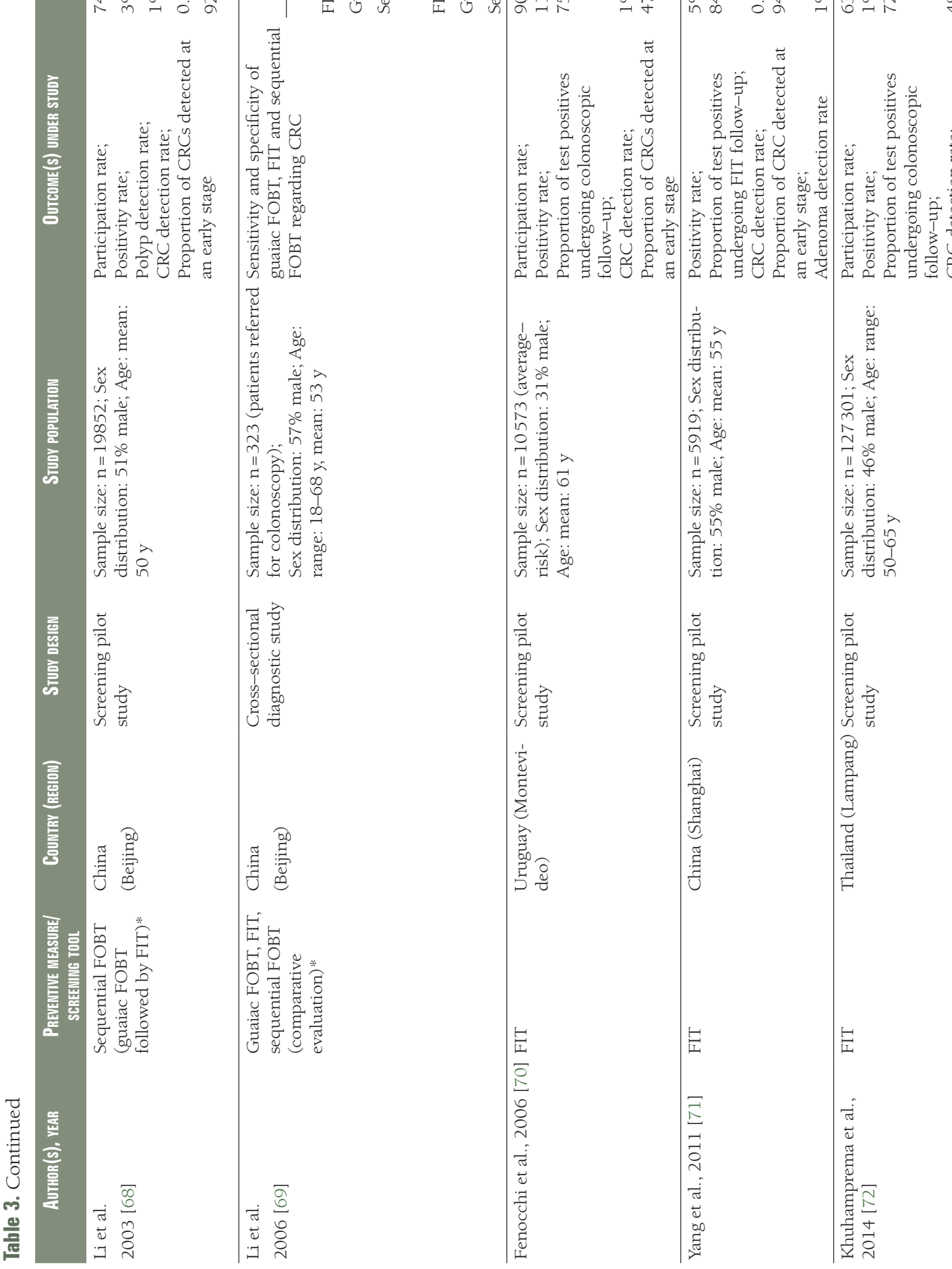

च

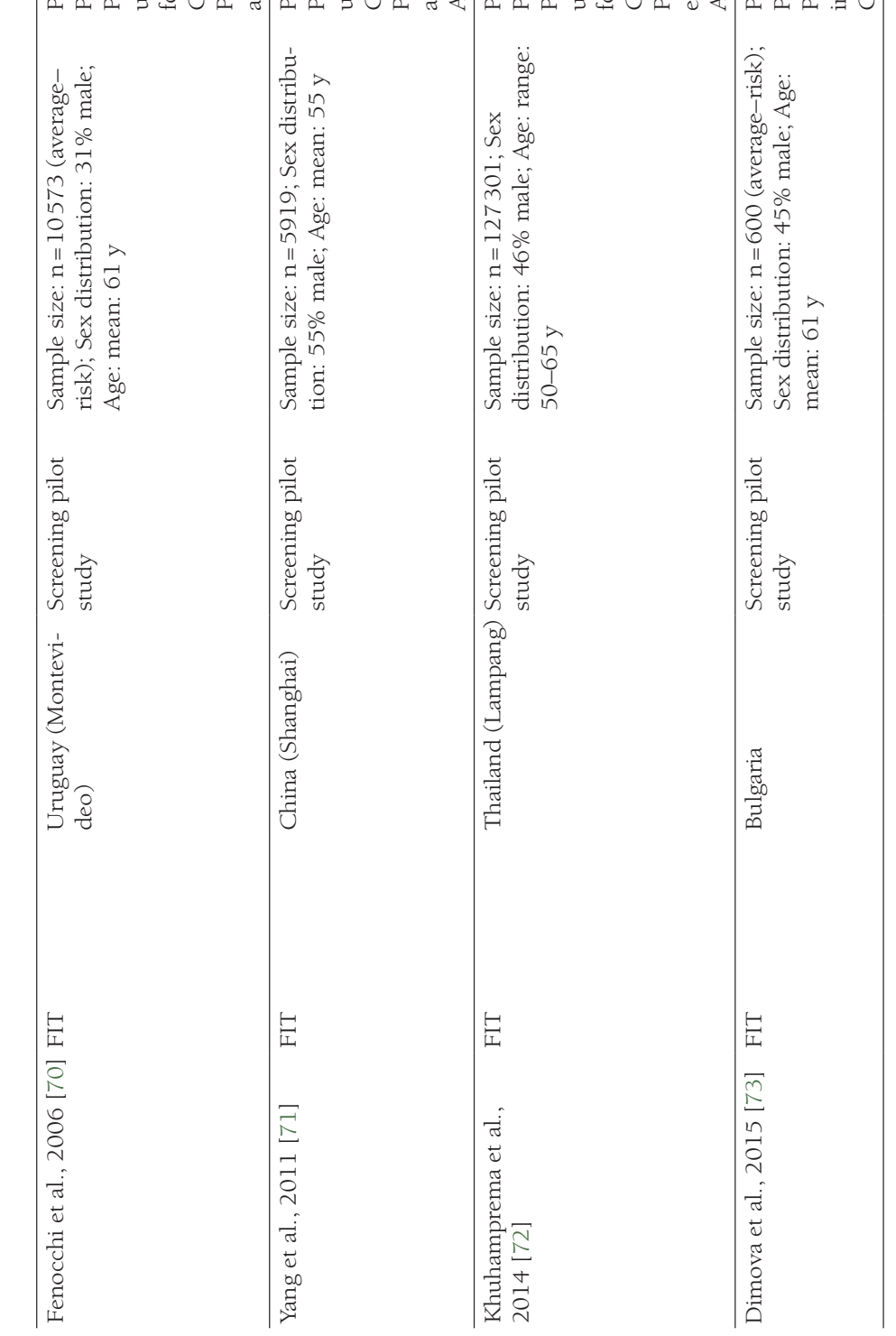




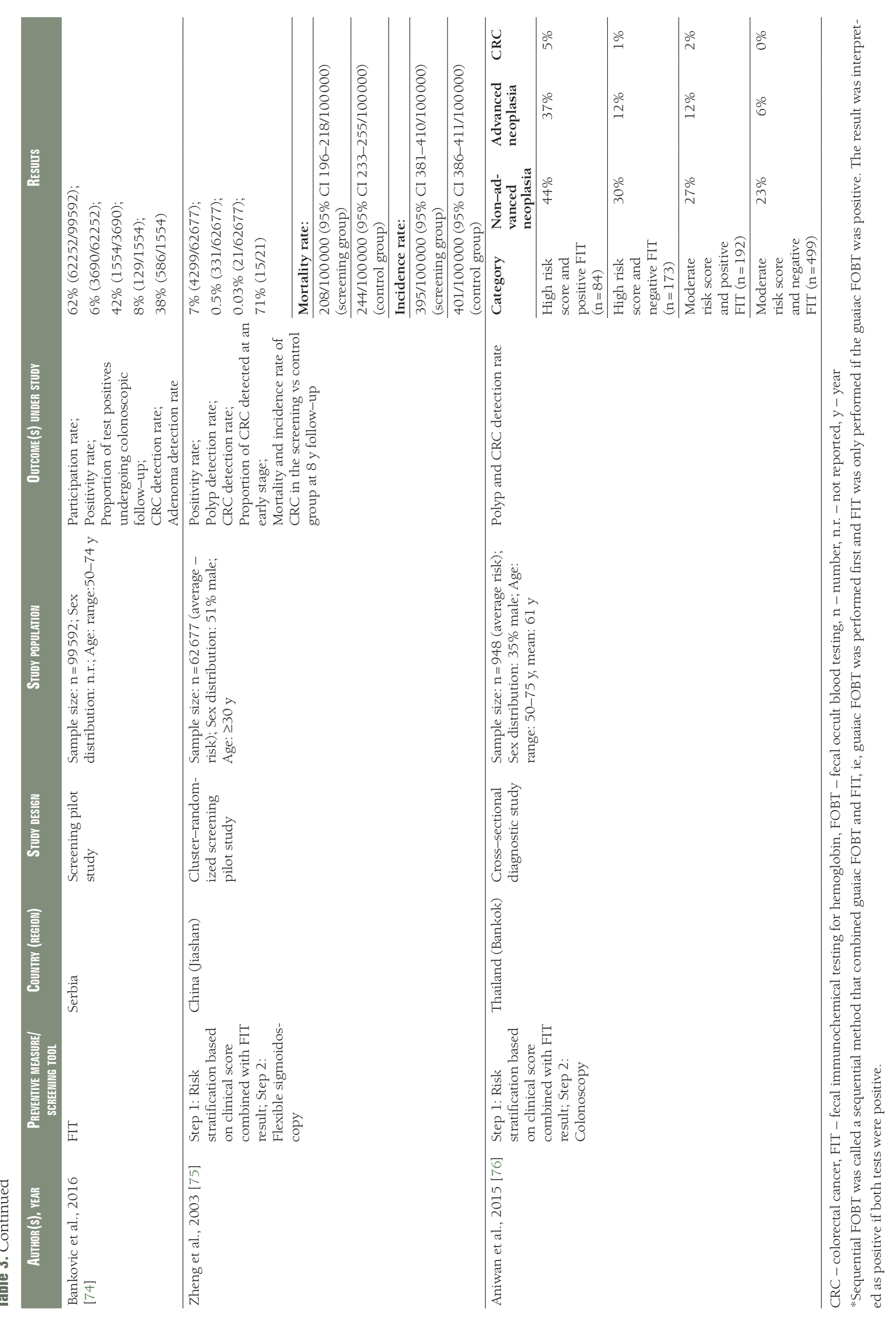


(WHO) has recommended that all infants receive the HBV vaccine as soon as possible after birth. As of 2013, 183 WHO member states have included HBV vaccination in their preventive programs [77]. While the various beneficial effects of these programs regarding HBV-related diseases are out of question, it will take more time to see their full effect on incidence and mortality of liver cancer, particularly in adults. The study by Wichajarn et al. [48] already observed an incidence reduction for hepatocellular carcinoma among children in Thailand, which confirms earlier reports from Taiwan [78]. A study from China reported an incidence reduction of $84 \%$ in a study population that reached early adulthood [38]. This also confirms earlier reports from Taiwan showing that the preventive effect of HBV vaccination extends from childhood to early adulthood [79].

Studies included in our review on the prevention of gastric and liver cancer by supplementation of vitamins or minerals in developing countries give the impression that there is a lack of effectiveness or not enough evidence yet to justify their translation into a preventive program. Most studies did not show an effect or were difficult to interpret. This is in line with results of supplementation trials conducted in Western countries that did not show beneficial effects either, such as the Selenium and Vitamin E Cancer Prevention Trial [80]. Apart from the lack of effectiveness, it is questionable whether preventive measures that require long-term and regular use of supplements would prove suitable for developing countries. Food or soil fortification may have more potential in terms of practicality, but of course this would become relevant only for measures with proven effectiveness and safety [81].

Practicality is also an important aspect to be discussed in the context of cancer screening in developing countries. The screening strategies included in this review, mainly focused on colorectal cancer, which is less amenable to primary prevention through risk factor modification as compared to gastric and liver cancer. Implementing population-based screening programs may be challenging in developing countries in view of resource constraints (eg, infrastructure, availability of equipment and trained personnel, costs). This notion is supported by the fact that substantial proportion of screening studies has been conducted in China that has more resources than many other developing countries. While most screening studies were limited to intermediate endpoints (eg, detection rates), Zahng et al. reported a reduction in liver cancer mortality by $40 \%$ for biannual serum alpha-fetoprotein testing in high risk groups (HBV infected or history of chronic hepatitis) after 5-10 screening rounds [56]. Targeting screening at high-risk groups rather than at average-risk persons may generally be a more doable approach for developing countries that seems worthwhile to be further explored, eg, also for colorectal cancer. To ensure practicality of such strategies, identification of risk groups needs to be based on easily obtainable information (eg, family history, lifestyle or basic clinical factors). This was exemplified by two studies that used a clinical risk score combined with FIT to identify risk groups that benefit most from colonoscopy $[75,76]$. However, when estimating the effectiveness of potential screening strategies in developing countries, the treatability of early cancer stages also requires consideration. In industrialized countries, an important argument in favor of screening is the better prognosis for early vs late stages, but this may not hold true in developing countries if, for example, surgical treatment options are limited [82].

To the best of our knowledge, there is no similar review that systematically summarizes studies on the prevention of gastric, liver and colorectal cancer in developing countries including long-term follow-up reports on these studies. Considerable variation in prevalence of various cancers between low- and highresource countries, extensive differences in operational settings and possibly also in compliance rates warrant to put a focus on strategies for cancer prevention specifically in developing countries. There are also limitations that should be noted. First, our search was restricted to papers published in English and we did not optimize our search for specific sub-questions such as HBsAg carrier state nor did we include the aspect of cost-effectiveness. Second, incomplete reporting of relevant information in original articles partly limited interpretability of the studies. Third, our review provides a descriptive summary of studies, while meta-analyses would have been beyond its scope. However, we consider our review an important pre-work that will facilitate the planning and conduct of such meta-analyses, particularly by providing information regarding heterogeneity between studies (in terms of the study designs, the target populations, the interventions, the follow-up periods, the outcomes etc.). Fourth, as for any review, we cannot rule out that publication bias has led to overestimating the beneficial effect of preventive measures. In the interpretation of this review it should also be noted that almost half of the studies were conducted in China, but developing countries considerably vary in their Human Development Index and aspects of effectiveness and feasibility may not be similar across countries.

In conclusion, there were a number of studies on gastric and liver cancer prevention in developing countries showing promising results after long-term follow-up. Important next steps include pooled metaanalyses as far as possible given the heterogeneity between studies as well as implementation research. 


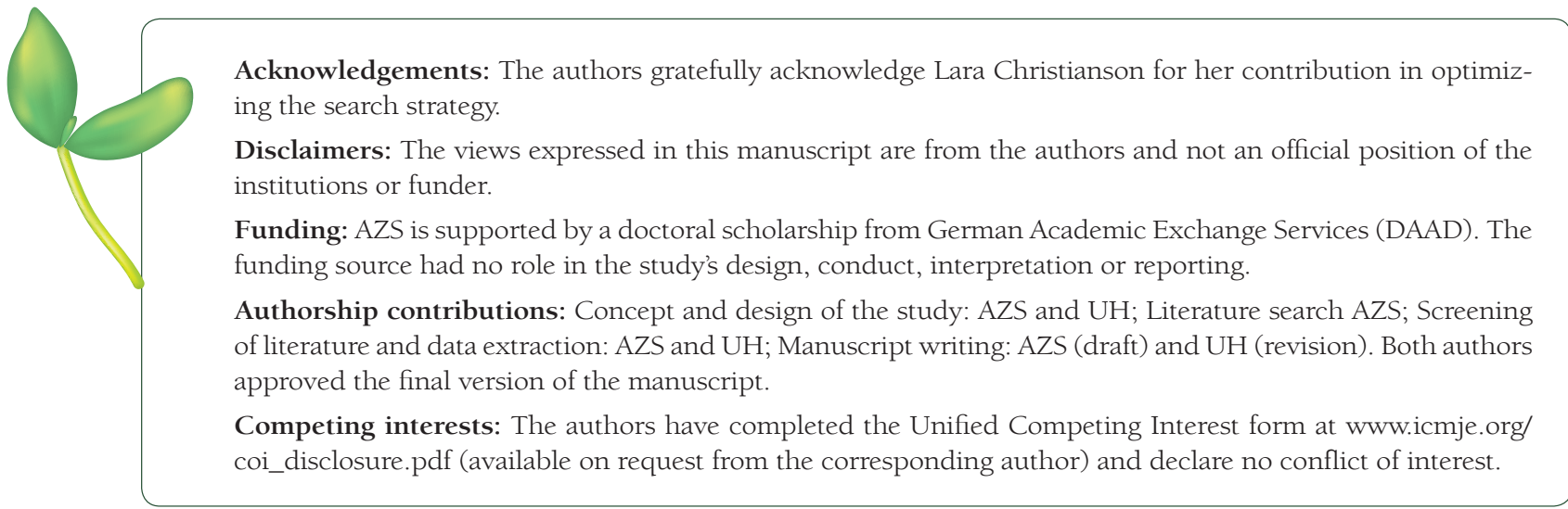

1 Ferlay J, Soerjomataram I, Ervik M, Dikshit R, Eser S, Mathers C, et al. GLOBOCAN 2012: Cancer incidence and mortality worldwide, version 1.0. IARC Cancer Base. Lyon: IARC, 2013. Available: http://globocan.iarc.fr/Pages/fact_sheets_ population.aspx. Accessed: 27 April 2015.

2 Bray F, Jemal A, Grey N, Ferlay J, Forman D. Global cancer transitions according to the Human Development Index (2008-2030): a population-based study. Lancet Oncol. 2012;13:790-801. Medline:22658655 doi:10.1016/S14702045(12)70211-5

3 National Cancer Institute. SEER Stat fact sheets 2012. Available: http://seer.cancer.gov/statfacts/html/. Accessed: 25 October 2015.

4 Blot WJ, Li J-Y, Taylor PR, Guo W, Dawsey S, Wang GQ, et al. Nutrition intervention trials in Linxian, China: supplementation with specific vitamin/mineral combinations, cancer incidence, and disease-specific mortality in the general population. J Natl Cancer Inst. 1993;85:1483-92. Medline:8360931 doi:10.1093/jnci/85.18.1483

5 Wang GQ, Dawsey SM, Li JY, Taylor PR, Li B, Blot WJ, et al. Effects of vitamin/mineral supplementation on the prevalence of histological dysplasia and early cancer of the esophagus and stomach: results from the General Population Trial in Linxian, China. Cancer Epidemiol Biomarkers Prev. 1994;3:161-6. Medline:8049638

6 Qiao YL, Dawsey SM, Kamangar F, Fan JH, Abnet CC, Sun XD, et al. Total and cancer mortality after supplementation with vitamins and minerals: follow-up of the Linxian General Population Nutrition Intervention Trial. J Natl Cancer Inst. 2009;101:507-18. Medline:19318634 doi:10.1093/jnci/djp037

7 Li J-Y, Taylor PR, Li B, Dawsey S, Wang G-Q, Ershow AG, et al. Nutrition Intervention Trials in Linxian, China: multiple vitamin/mineral supplementation, cancer incidence, and disease-specific mortality among adults with esophageal dysplasia. J Natl Cancer Inst. 1993;85:1492-8. Medline:8360932 doi:10.1093/jnci/85.18.1492

8 Wang GQ, Dawsey SM, Taylor PR, Li J-Y, Blot WJ, Li B, et al. Effects of vitamin/mineral supplementation on the prevalence of histological dysplasia and early cancer of the esophagus and stomach: results from the Dysplasia Trial in Linxian, China. Cancer Epidemiol Biomarkers Prev. 1994;3:161-6. Medline:8049638

9 Wang JB, Abnet CC, Fan JH, Qiao YL, Taylor PR. The randomized Linxian Dysplasia Nutrition Intervention Trial after 26 years of follow-up: no effect of multivitamin supplementation on mortality. JAMA Intern Med. 2013;173:1259-61. Medline:23712839 doi:10.1001/jamainternmed.2013.6066

10 Li H, Li H-q, Wang Y, Xu H-x, Fan W-t, Wang M-l, et al. An intervention study to prevent gastric cancer by micro-selenium and large dose of allitridum. Chin Med J (Engl). 2004;117:1155-60. Medline:15361287

11 Plummer M, Vivas J, Lopez G, Bravo JC, Peraza S, Carillo E, et al. Chemoprevention of precancerous gastric lesions with antioxidant vitamin supplementation: a randomized trial in a high-risk population. J Natl Cancer Inst. 2007;99:137-46. Medline:17227997 doi:10.1093/jnci/djk017

12 Correa P, Fontham ETH, Bravo JC, Bravo LE, Ruiz B, Zarama G, et al. Chemoprevention of gastric dysplasia: randomized trial of antioxidant supplements and anti-Helicobacter pylori therapy. J Natl Cancer Inst. 2000;92:1881-8. Medline:11106679 doi:10.1093/jnci/92.23.1881

13 Sung JJY, Lin SR, Ching JYL, Zhou LY, To KF, Wang RT, et al. Atrophy and intestinal metaplasia one year after cure of $H$. pylori infection: a prospective, randomized study. Gastroenterology. 2000;119:7-14. Medline:10889149 doi:10.1053/ gast. 2000.8550

14 Zhou L, Lin S, Ding S, Huang X, Jin Z, Cui R, et al. Relationship of Helicobacter pylori eradication with gastric cancer and gastric mucosal histological changes: a 10-year follow-up study. Chin Med J (Engl). 2014;127:1454-8. Medline:24762588

15 Guo H-Q, Guan P, Shi H-L, Zhang X, Zhou B-S, Yuan Y. Prospective cohort study of comprehensive prevention to gastric cancer. World J Gastroenterol. 2003;9:432-6. Medline:12632491 doi:10.3748/wjg.v9.i3.432

16 Zhou L, Sung JJY, Lin SR, Jin Z, Ding SG, Huang XB, et al. A five-year follow-up study on the pathological changes of gastric mucosa after H-pylori eradication. Chin Med J (Engl). 2003;116:11-4. Medline:12667379

17 Wong BC, Lam SK, Wong WM, Chen JS, Zheng TT, Feng RE, et al. Helicobacter pylori eradication to prevent gastric cancer in high-risk region of China. JAMA. 2004;291:187-94. Medline:14722144 doi:10.1001/jama.291.2.187 
18 Ley C, Mohar A, Guarner J, Herrera-Goepfert R, Figueroa LS, Halperin D, et al. Helicobacter pylori eradication and gastric preneoplastic conditions: a randomized, double-blind, placebo-controlled trial. Cancer Epidemiol Biomarkers Prev. 2004;13:4-10. Medline:14744726 doi:10.1158/1055-9965.EPI-03-0124

19 You WC, Brown LM, Zhang L, Li JY, Jin ML, Chang YS, et al. Randomized double-blind factorial trial of three treatments to reduce the prevalence of precancerous gastric lesions. J Natl Cancer Inst. 2006;98:974-83. Medline:16849680 doi:10.1093/jnci/djj264

20 Ma JL, Zhang L, Brown LM, Li JY, Shen L, Pan KF, et al. Fifteen-year effects of Helicobacter pylori, garlic, and vitamin treatments on gastric cancer incidence and mortality. J Natl Cancer Inst. 2012;104:488-92. Medline:22271764 doi:10.1093/jnci/djs003

21 Li WQ, Ma JL, Zhang L, Brown LM, Li JY, Shen L, et al. Effects of Helicobacter pylori treatment on gastric cancer incidence and mortality in subgroups. J Natl Cancer Inst. 2014;106:dju116. Medline:24925350 doi:10.1093/jnci/dju116

22 Ji F, Wang ZW, Ning JW, Wang QY, Chen JY, Li YM. Effect of drug treatment on hyperplastic gastric polyps infected with Helicobacter pylori: a randomized, controlled trial. World J Gastroenterol. 2006;12:1770-3. Medline:16586550 doi:10.3748/wjg.v12.i11.1770

23 Sari Y-S. H pylori: treatment for the patient only or the whole family? World J Gastroenterol. 2008;14:1244. Medline:18300351 doi:10.3748/wjg.14.1244

24 Wong BC, Zhang L, Ma JL, Pan KF, Li JY, Shen L, et al. Effects of selective COX-2 inhibitor and Helicobacter pylori eradication on precancerous gastric lesions. Gut. 2012;61:812-8. Medline:21917649 doi:10.1136/gutjnl-2011-300154

25 Massarrat S, Haj-sheykholeslami A, Mohamadkhani A, Zendehdel N, Rakhshani N, Stolte M, et al. Precancerous conditions after H.pylori eradication: a randomized double blind study in first degree relatives of gastric cancer patients. Arch Iran Med. 2012;15:664-9. Medline:23102241

26 Pan KF, Zhang L, Gerhard M, Ma JL, Liu WD, Ulm K, et al. A large randomised controlled intervention trial to prevent gastric cancer by eradication of Helicobacter pylori in Linqu County, China: baseline results and factors affecting the eradication. Gut. 2016;65:9-18. Medline:25986943 doi:10.1136/gutjnl-2015-309197

27 Qin DX, Wang GQ, Yuan FL, Tang MZ, Li MS, Zhang ZL, et al. Screening for upper digestive tract cancer with an occult blood bead detector. Cancer. 1988;62:1030-4. Medline:3409165 doi:10.1002/1097-0142(19880901)62:5<1030::AIDCNCR2820620533>3.0.CO;2-S

28 Qin DX, Wang GQ, Wang ZY. Double blind randomized trial on occult blood bead (OBB) and gastroscopy-pathology screening for gastro-oesophageal cancer. Eur J Cancer Prev. 1997;6:158-61. Medline:9237065

29 Pisani P, Oliver WE, Parkin DM, Alvarez N, Vivas J. Case-control study of gastric cancer screening in Venezuela. Br J Cancer. 1994;69:1102-5. Medline:8198977 doi:10.1038/bjc.1994.216

30 Rosero-Bixby L, Sierra R. X-ray screening seems to reduce gastric cancer mortality by half in a community-controlled trial in Costa Rica. Br J Cancer. 2007;97:837-43. Medline:17912238 doi:10.1038/sj.bjc.6603729

31 Zhang Z, Wan J, Zhu C, Wang M, Zhao D, Fu Y, et al. Direct gastroscopy for detecting gastric cancer in the elderly. Chin Med J (Engl). 2002;115:117-8. Medline:11930642

$32 \mathrm{Lu}$ YF, Liu ZC, Li ZH, Ma WH, Wang FR, Zhang YB, et al. Esophageal/gastric cancer screening in high-risk populations in Henan Province, China. Asian Pac J Cancer Prev. 2014;15:1419-22. Medline:24606476 doi:10.7314/ APJCP.2014.15.3.1419

33 Zheng X, Mao X, Xu K, Lu L, Peng X, Wang M, et al. Massive endoscopic screening for esophageal and gastric cancers in a high-risk area of China. PLoS One. 2015;10:e0145097. Medline:26699332 doi:10.1371/journal.pone.0145097

34 Chen Q, Yu L, Hao CQ, Wang JW, Liu SZ, Zhang M, et al. Effectiveness of endoscopic gastric cancer screening in a rural area of Linzhou, China: results from a case-control study. Cancer Med. 2016;5:2615-22. Medline:27367362 doi:10.1002/ cam4.812

35 Maupas P, Chiron JP, Barin F, Coursaget P. Efficacy of hepatitis B vaccine in prevention of early HBsAg carrier state in children. Lancet. 1981;1:289-92. Medline:6109938 doi:10.1016/S0140-6736(81)91908-5

36 Sun TT, Chu YR, Ni ZH, Lu JH, Huang F, Ni ZP, et al. A pilot study on universal immunization of newborn infants in an area of hepatitis B virus and primary hepatocellular carcinoma prevalence with low dose of hepatitis B vaccine. J Cell Physiol Suppl. 1986;4:83-90. Medline:3018008

37 Sun Z, Zhu Y, Stjernsward J, Hilleman M, Collins R, Zhen Y, et al. Design and compliance of HBV vaccination trial on newbrons to prevent hepatocellular carcinoma and 5-year results of its pilot study. Cancer Detect Prev. 1991;15:313-8. Medline: 1665400

38 Qu C, Chen T, Fan C, Zhan Q, Wang Y, Lu J, et al. Efficacy of neonatal HBV vaccination on liver cancer and other liver diseases over 30-year follow-up of the Qidong hepatitis B intervention study: a cluster randomized controlled trial. PLoS Med. 2014;11:e1001774. Medline:25549238 doi:10.1371/journal.pmed.1001774

39 Chotard J, Inskip HM, Hall AJ, Loik F, Mendy M, Whittle H, et al. The Gambia hepatitis intervention study: follow-up of a cohort of children vaccinated against hepatitis B. J Infect Dis. 1992;166:764-8. Medline:1388196 doi:10.1093/ infdis/166.4.764

40 Fortuin M, Chotard J, Jack AD, Maine NP, Mendy M, Hall AJ, et al. Efficacy of hepatitis B vaccine in the Gambian expanded programme on immunization. Lancet. 1993;341:1129-31. Medline:8097813 doi:10.1016/0140-6736(93)93137-P

41 Viviani S, Jack A, Hall AJ, Maine N, Mendy M, Motesano R, et al. Hepatitis B vaccination in infancy in the Gambia: protection against carriage at 9 years of age. Vaccine. 1999;17:2946-50. Medline:10462228 doi:10.1016/S0264410X(99)00178-4 
42 van der Sande MAB, Waight PA, Mendy M, Zaman S, Kaye S, Sam O, et al. Long-term protection against HBV chronic carriage of Gambian adolescents vaccinated in infancy and immune response in HBV booster trial in adolescence. PLoS One. 2007;2:e753. Medline:17710152 doi:10.1371/journal.pone.0000753

43 Peto TJ, Mendy ME, Lowe Y, Webb EL, Whittle HC, Hall AJ. Efficacy and effectiveness of infant vaccination against chronic hepatitis B in the Gambia Hepatitis Intervention Study (1986-90) and in the nationwide immunisation program. BMC Infect Dis. 2014;14:7. Medline:24397793 doi:10.1186/1471-2334-14-7

44 Whittle HC, Inskip H, Hall AJ, Mendy M, Dowens RH. S. Vaccination against hepatitis B and protection against chronic viral carriage in The Gambia. Lancet. 1991;337:747-50. Medline:1672389 doi:10.1016/0140-6736(91)91367-4

45 Whittle HC, Maine N, Pilkington J, Mendy M, Fortuin M, Bunn J, et al. Long-term efficacy of continuing hepatitis B vaccination in infancy in two Gambian villages. Lancet. 1995;345:1089-92. Medline:7715343 doi:10.1016/S01406736(95)90822-6

46 Whittle H, Jaffar S, Wansbrough M, Mendy M, Dumpis U, Collinson A, et al. Observational study of vaccine efficacy 14 years after trial of hepatitis B vaccination in Gambian children. BMJ. 2002;325:569-73. Medline:12228132 doi:10.1136/ bmj.325.7364.569

47 Mendy M, Peterson I, Hossin S, Peto T, Jobarteh ML, Jeng-Barry A, et al. Observational study of vaccine efficacy 24 years after the start of Hepatitis B vaccination in two Gambian villages: no need for a booster dose. PLoS One. 2013;8:e58029. Medline:23533578 doi:10.1371/journal.pone.0058029

48 Wichajarn K, Kosalaraksa P, Wiangnon S. Incidence of hepatocellular carcinoma in children in Khon Kaen before and after National Hepatitis B Vaccine Program. Asian Pac J Cancer Prev. 2008;9:507-9. Medline:18990029

49 Shen LP, Zhang Y, Wang F, Zhang S, Yang JY, Fang KX, et al. Epidemiological changes in hepatitis B prevalence in an entire population after 20 years of the universal HBV vaccination programme. Epidemiol Infect. 2011;139:1159-65. Medline:21156099 doi:10.1017/S0950268810002827

50 Posuwan N, Wanlapakorn N, Sa-nguanmoo P, Wasitthankasem R, Vichaiwattana P, Klinfueng S, et al. The success of a universal Hepatitis B immunization program as part of Thailand's EPI after 22 years' implementation. PLoS One. 2016;11:e0150499. Medline:26938736 doi:10.1371/journal.pone.0150499

51 Yu S-Y, Zhu Y-J, Li W-G, Huangqi U-S, Zhi-Huang C, Zhang Q-N, et al. A preliminary report on the intervention trials of primary liver cancer in high-risk populations with nutritional supplementation of selenium in china. Biol Trace Elem Res. 1991;29:289-94. Medline:1726411 doi:10.1007/BF03032685

52 Yu SY, Zhu YJ, Li W-G. Protective role of selenium against hepatitis B virus and primary liver cancer in Qidong. Biol Trace Elem Res. 1997;56:117-24. Medline:9152515 doi:10.1007/BF02778987

53 Qu CX, Kamangar F, Fan JH, Yu BB, Sun XD, Taylor PB, et al. Chemoprevention of primary liver cancer: A randomized, double-blind trial in Linxian, China. J Natl Cancer Inst. 2007;99:1240-7. Medline:17686823 doi:10.1093/jnci/djm084

54 Yang B, Zhang B, Xu Y, Wang W, Shen Y, Zhang A, et al. Prospective study of early detection for primary liver cancer. J Cancer Res Clin Oncol. 1997;123:357-60. Medline:9222303 doi:10.1007/BF01438313

55 Zhang B, Yang B. Combined fetoprotein testing and ultrasonography as a screening test for primary liver cancer. J Med Screen. 1999;6:108-10. Medline:10444731 doi:10.1136/jms.6.2.108

56 Zhang BH, Yang BH, Tang ZY. Randomized controlled trial of screening for hepatocellular carcinoma. J Cancer Res Clin Oncol. 2004;130:417-22. Medline:15042359 doi:10.1007/s00432-004-0552-0

57 Chen JG, Parkin DM, Chen QG, Lu JH, Shen QJ, Zhang BC, et al. Screening for liver cancer: results of a randomised controlled trial in Qidong, China. J Med Screen. 2003;10:204-9. Medline:14738659 doi:10.1258/096914103771773320

58 Eltabbakh M, Zaghla H, Abdel-Razek W, Elshinnawy H, Ezzat S, Gomaa A, et al. Utility and cost-effectiveness of screening for hepatocellular carcinoma in a resource-limited setting. Med Oncol. 2015;32:432. Medline:25502085 doi:10.1007/ s12032-014-0432-7

59 Zheng GM, Choi BCK, Yu XR, Zou RB, Shao YW, Ma XY. Mass-screening for rectal neoplasm in Jiashan-County, China. J Clin Epidemiol. 1991;44:1379-85. Medline:1753269 doi:10.1016/0895-4356(91)90099-U

60 Zheng S, Liu X-Y, Ding K-F, Wang L-B, Qiu P-L, Ding X-F, et al. Reduction of the incidence and mortality of rectal cancer by polypectomy: a prospective cohort study in Haining County. World J Gastroenterol. 2002;8:488-92. Medline:12046076 doi:10.3748/wjg.v8.i3.488

61 Wan J, Zhang Z-Q, Zhu C, Wang M-W, Zhao D-H, Fu Y-H, et al. Colonoscopic screening and follow up for colorectal cancer in the elderly. World J Gastroenterol. 2002;8:267-9. Medline:11925605

62 Croitoru L, Trifan A, Maxim MR, Girleanu I, Hulub A, Dimache M, et al. Colonoscopic screening of asymptomatic firstdegree relatives of colorectal cancer patients. Rev Med Chir Soc Med Nat Iasi. 2010;114:683-6. Medline:21235115

63 Arafa MA, Sallam S, Jriesat S. Colorectal cancer screening amongst first degree relatives of colon cancer cases in Jordan. Asian Pac J Cancer Prev. 2011;12:1007-11. Medline:21790242

64 Aswakul P, Prachayakul V, Lohsiriwat V, Bunyaarunnate T, Kachintorn U. Screening colonoscopy from a large single center of Thailand - something needs to be changed? Asian Pac J Cancer Prev. 2012;13:1361-4. Medline:22799332 doi:10.7314/APJCP.2012.13.4.1361

65 Ionescu EM, Nicolaie T, Gologan SI, Mocanu A, Ditescu C, Arbanas T, et al. Opportunistic colorectal cancer screening using colonoscopy. Comparative results between two historical cohorts in Bucharest, Romania. J Gastrointestin Liver Dis. 2015;24:171-6. Medline:26114176

66 Panic N, Rosch T, Smolovic B, Radunovic M, Bulajic M, Pavlovic-Markovic A, et al. Colorectal cancer screening in a lowincidence area: general invitation versus family risk targeting: a comparative study from Montenegro. Eur J Gastroenterol Hepatol. 2015;27:1222-5. Medline:26067224 doi:10.1097/MEG.0000000000000415 
67 Siripongpreeda B, Mahidol C, Dusitanond N, Sriprayoon T, Muyphuag B, Sricharunrat T, et al. High prevalence of advanced colorectal neoplasia in the Thai population: a prospective screening colonoscopy of 1,404 cases. BMC Gastroenterol. 2016;16:101. Medline:27553627 doi:10.1186/s12876-016-0526-0

68 Li S, Nie Z, Li N, Li J, Zhang P, Yang Z, et al. Colorectal cancer screening for the natural population of Beijing with sequential fecal occult blood test: a multicenter study. Chin Med J (Engl). 2003;116:200-2. Medline:12775229

69 Li S, Wang H, Hu J, Li N, Liu Y, Wu Z, et al. New immunochemical fecal occult blood test with two-consecutive stool sample testing is a cost-effective approach for colon cancer screening: results of a prospective multicenter study in Chinese patients. Int J Cancer. 2006;118:3078-83. Medline:16425283 doi:10.1002/ijc.21774

70 Fenocchi E, Martinez L, Tolve J, Montano D, Rondan M, Parra-Blanco A, et al. Screening for colorectal cancer in Uruguay with immunochemical faecal occult blood test. Eur J Cancer Prev. 2006;15:384-90. Medline:16912566 doi:10.1097/00008469-200610000-00002

71 Yang H, Ge Z, Dai J, Li X, Gao Y. Effectiveness of the immunofecal occult blood test for colorectal cancer screening in a large population. Dig Dis Sci. 2011;56:203-7. Medline:20458621 doi:10.1007/s10620-010-1264-8

72 Khuhaprema T, Sangrajrang S, Lalitwongsa S, Chokvanitphong V, Raunroadroong T, Ratanachu-ek T, et al. Organised colorectal cancer screening in Lampang Province, Thailand: preliminary results from a pilot implementation programme. BMJ Open. 2014;4:e003671. Medline:24435889 doi:10.1136/bmjopen-2013-003671

73 Tsvetanova Dimova RT, Dimitrova DD, Levterova BA, Dimov RS, Semerdjieva MA, Tamovska MF, et al. Feasibility of immunochemical faecal occult blood testing for colorectal cancer screening in Bulgaria. J BUON. 2015;20:413-20. Medline:26011330

74 Bankovic-Lazarevic D, Krivokapic Z, Barisic G, Jovanovic V, Ilic D, Veljkovic M. Organized colorectal cancer screening in Serbia - the first round within 2013-2014. Vojnosanit Pregl. 2016;73:360-7. doi:10.2298/VSP150421113B

75 Zheng S, Chen K, Liu XY, Ma XY, Yu H, Chen K, et al. Cluster randomization trial of sequence mass screening for colorectal cancer. Dis Colon Rectum. 2003;46:51-8. Medline:12544522 doi:10.1007/s10350-004-6496-2

76 Aniwan S, Rerknimitr R, Kongkam P, Wisedopas N, Ponuthai Y, Chaithongrat S, et al. A combination of clinical risk stratification and fecal immunochemical test results to prioritize colonoscopy screening in asymptomatic participants. Gastrointest Endosc. 2015;81:719-27. Medline:25708760 doi:10.1016/j.gie.2014.11.035

77 World Health Organization. Hepatitis B fact sheet: 2015. Available: http://www.who.int/mediacentre/factsheets/fs204/ en/. Accessed: 15 February 2016.

78 Chang MH, Chen CJ, Lai MS, Hsu HM, Wu TC, Kong MS, et al. Universal hepatitis B vaccination in Taiwan and the incidence of hepatocellular carcinoma in children. N Engl J Med. 1997;336:1855-9. Medline:9197213 doi:10.1056/ NEJM199706263362602

79 Chang MH, You SL, Chen CJ, Liu CJ, Lee CM, Lin SM, et al. Decreased incidence of hepatocellular carcinoma in hepatitis B vaccinees: a 20-year follow-up study. J Natl Cancer Inst. 2009;101:1348-55. Medline:19759364 doi:10.1093/jnci/ djp288

80 Lippman SM, Klein EA, Goodman PJ, Lucia MS, Thompson IM, Ford LG, et al. Effect of selenium and vitamin E on risk of prostate cancer and other cancers: the Selenium and Vitamin E Cancer Prevention Trial (SELECT). JAMA. 2009;301:3951. Medline:19066370 doi:10.1001/jama.2008.864

81 Ma G, Jin Y, Li Y, Zhai F, Kok FJ, Jacobsen E, et al. Iron and zinc deficiencies in China: what is a feasible and cost-effective strategy? Public Health Nutr. 2008;11:632-8. Medline:17894916 doi:10.1017/S1368980007001085

82 Sullivan R, Alatise OI, Anderson BO, Audisio R, Autier P, Aggarwal A, et al. Global cancer surgery: delivering safe, affordable, and timely cancer surgery. Lancet Oncol. 2015;16:1193-224. Medline:26427363 doi:10.1016/S14702045(15)00223-5 